\title{
Resource and waste quantification scenarios for wind turbine decommissioning in the United Kingdom
}

\author{
Kiran Tota-Maharaj $^{1}$ D $\cdot$ Alexander McMahon $^{2}$
}

Received: 14 May 2020 / Revised: 16 October 2020 / Accepted: 26 October 2020 / Published online: 16 December 2020

(c) The Author(s) 2020

\begin{abstract}
Wind power produces more electricity than any other form of renewable energy in the United Kingdom (UK) and plays a key role in decarbonisation of the grid. Although wind energy is seen as a sustainable alternative to fossil fuels, there are still several environmental impacts associated with all stages of the lifecycle of a wind farm. This study determined the material composition for wind turbines for various sizes and designs and the prevalence of such turbines over time, to accurately quantify waste generation following wind turbine decommissioning in the UK. The end of life stage is becoming increasingly important as a rapid rise in installation rates suggests an equally rapid rise in decommissioning rates can be expected as wind turbines reach the end of their 20-25-year operational lifetime. Waste data analytics were applied in this study for the UK in 5-year intervals, stemming from 2000 to 2039. Current practices for end of life waste management procedures have been analysed to create baseline scenarios. These scenarios have been used to explore potential waste management mitigation options for various materials and components such as reuse, remanufacture, recycling, and heat recovery from incineration. Six scenarios were then developed based on these waste management options, which have demonstrated the significant environmental benefits of such practices through quantification of waste reduction and greenhouse gas (GHG) emissions savings. For the 2015-2019 time period, over 35 kilotonnes of waste are expected to be generated annually. Overall waste is expected to increase over time to more than 1200 kilotonnes annually by 2039 . Concrete is expected to account for the majority of waste associated with wind turbine decommissioning initially due to foundations for onshore turbines accounting for approximately $80 \%$ of their total weight. By 2035-2039, steel waste is expected to account for almost $50 \%$ of overall waste due to the emergence of offshore turbines, the foundations of which are predominantly made of steel.
\end{abstract}

Keywords Wind power $\cdot$ Energy infrastructure $\cdot$ Waste management $\cdot$ Turbine decommissioning $\cdot$ Life cycle $\cdot$ Greenhouse gas emissions (GHG)

Electronic supplementary material The online version of this article (https://doi.org/10.1007/s42768-020-00057-6) contains supplementary material, which is available to authorized users.

Kiran Tota-Maharaj

k.tota-maharaj@aston.ac.uk

Alexander McMahon

alex.mcmahon@aecom.com

1 Department of Civil Engineering, Aston Infrastructure and Sustainable Engineering School, College of Engineering and Physical Sciences, Aston University Birmingham, Aston Triangle, Birmingham B4 7ET, UK

2 AECOM, Bristol BS1 6NA, UK

\section{Introduction}

Climate change is seen as one of the biggest threats faced by the world due to the associated negative impacts upon natural and human environments [1,2]. $\mathrm{CO}_{2}$ emissions from the combustion of fossil fuels make the greatest contribution to climate change worldwide [3]. Fossil fuels are often used directly for heat and power while also being used to fuel power plants for electricity generation [4]. Agreements and targets have been put in place by governments and intergovernmental departments to combat the negative effects of climate change, such as the Kyoto Protocol [5], Paris 
Agreement [6] and, within the UK, the Climate Change Act [7]. Each takes a slightly different approach, but all share the common goal of reducing greenhouse gas (GHG) emissions. To meet the targets, or 'carbon budgets', laid out by the Climate Change Act [7], a Carbon Plan was implemented in the UK [8] The electrification of road vehicles and rail networks are key aims laid out within the Carbon Plan. If these aims are to be met, the power sector, which is already the largest source of the UK's emissions [8], will need to increase output, therefore, increasing emissions. Increased movement from fossil fuels to renewable energy is regarded as the solution to this issue [8]. Great progress has been made here, with low carbon sources (nuclear and renewable energy) producing more electricity than fossil fuels in 2017 as described by the Carbon brief [9]. Wind power is the leading renewable energy source, accounting for $14.6 \%$ of the UK's power generation and is, therefore, going to have a vital role in meeting future carbon budgets and reducing the negative effects of climate change [9].

\section{Wind power in the United Kingdom (UK)}

Vertical-axis wind turbines were first developed around 5000 years ago $[10,11]$. The first horizontal-axis wind turbines appeared in England around the twelfth century and were then among the most important driving engines, second to the water wheel $[10,11]$. These turbines soon spread throughout northern Europe and were adapted for various purposes, including water pumping, irrigation, and driving mills $[10,11]$. In the year 1888 saw the first large wind turbine for electricity generation in Cleveland, Ohio, with a $12 \mathrm{~kW}$ capacity [11]. Initially, these turbines facilitated the mechanisation of agriculture; however, with the electrification of the industrialised world, wind turbines could not compete economically with fossil fuelled power plants [12]. Fossil fuels were the main source of electricity during the industrialisation of the west until two oil crises in the 1970s caused fuel shortages, leading to increased wind power utilisation in the US and parts of Europe [12]. Wind power then evolved into large-scale, interconnected power generation $[11,12]$. The first wind farm in the UK was installed in Delabole, Cornwall in 1991 [13]. Since then, wind turbine sizes have increased dramatically to increase power output, making them competitive with fossil fuels in some cases as reported by the Berkeley Lab [14]. At present, the size of onshore wind turbines is often limited by the capacity of vehicles and roads to facilitate transportation of turbines to the site [15]. Offshore turbines, however, have fewer size restrictions and are generally much larger than onshore turbines, meaning larger capital costs are justified by increased power output $[14,15]$. As wind turbines become more competitive with fossil fuels, wind power becomes an economic asset, rather than simply an opportunity for the decarbonisation of the UK's energy supply. Their proliferation is, therefore, sure to continue.

The onshore wind potential of the UK is among the highest in Europe, with Scotland and Northern Ireland having the highest potential, followed by Wales and England [16]. Although the data and methods used by Troen and Petersen [16] are almost 30 years, these findings were confirmed by Eerens and Visser [17]. They (Eerens and Visser [17]) also modelled the distribution of full-load hours (the required hours spent at full capacity to achieve the annual yield) across Europe, as a way of comparing turbines and sites with different capacities. The full-load hours achieved onshore in the UK are, again, among the best in Europe, while those achieved offshore are higher still. The offshore areas modelled by Eerens and Visser [17] only cover the areas with depths of $<50 \mathrm{~m}$ as current offshore wind turbine structures are limited to such depths [18], with the exception of the Hywind Scotland Pilot Park, where 5 turbines with floating spar foundations are being demonstrated at a depth of 95-120 m [19]. This depth limitation means only certain offshore areas around the UK are available for development. These areas include the south-east and north-west coasts of England, most of the Welsh coastline, the northern and western coastlines of Scotland, and a small area of the north-eastern coast of Northern Ireland [20]. The enormous wind power potential within the UK represents a great opportunity for further wind power development to continue to decarbonise the UK's energy supply.

\section{Problems associated with waste from energy infrastructure}

Wind turbines generally produce no direct $\mathrm{CO}_{2}$ emissions; however, there are various environmental impacts associated with their manufacture, installation, and end of life (EoL) stages [21]). If wind power is to continue to produce an increasing amount of the UK's energy, improvements must be made in these areas to maximise sustainability. The EoL stage will become increasingly important over the coming decades as a rapid rise in installation rates since the 1990s can be expected to be mirrored by an equally rapid rise in decommissioning rates as turbines reach the end of their 20-25-year operational lifetime [22, 23]. The aim of this research project was to accurately calculate the volumes of waste expected to be produced by the wind power industry over the coming decades as a result of site decommissioning, to allow decision-makers to implement appropriate waste management procedures. The objectives were to discover the material compositions of various wind turbine designs in the UK, calculate the volumes of waste generated from turbine decommissioning and demonstrate the importance of improved waste management processes. 


\section{Waste calculations}

To calculate the quantity of waste expected over the coming decades, current installed capacity and different turbine material compositions have been analysed. Kim et al. [24] noted in the future there will be the acceleration of wind energy technology developments across Europe including the UK with an improvement of resource efficiency. Critical materials are used significantly for renewable energy systems such as wind turbines. Hence it is important to quantify and estimate the stocks and flows of materials within the sector. The UK Wind Energy Database [25] contains information about all UK wind farm projects. These projects can be organised by number of turbines, date of installation, capacity, region, and status (such as whether it is operational). Only operational sites have been assessed as including those still being planned would have added uncertainty to the results as plans are subject to change. Organising the projects by date enabled expected waste to be presented by year and in 5-year intervals. This not only allowed predictions of total waste from currently installed turbines, but also time periods in which it can be expected.

The Wind Power Database [2] was then used to find the specific models installed at each site for the largest 140 wind farms, accounting for $>50 \%$ of all wind turbines installed in the UK. This allowed for more accurate estimations of material compositions by, where possible, analysing the material compositions of the most common turbine models, or turbines made by the most common manufacturers. Much like the UK Wind Energy Database, the database by The Wind Power [25] and information gathered from the Wind Power Offshore [26] also contained relevant information such as site capacity and the number of turbines. Where the two databases contained conflicting information, internet research has been conducted to resolve any discrepancies and maximise accuracy. Internet research has also been conducted to fill any gaps in the data within these databases, particularly regarding turbine models installed as this information was often unavailable.

Life cycle assessments (LCAs) were used to determine the material compositions of onshore wind turbines of various capacities and designs. The LCAs covered a total of 26 wind turbines, ranging from $5 \mathrm{~kW}$ to $5 \mathrm{MW}$, and the patterns observed have been used to estimate the material compositions of all of the onshore wind turbines installed in the UK based on their capacity. Few LCAs were available for offshore wind turbines, so the material composition of the tower, nacelle, blades and hub of offshore turbines have been modelled based on the patterns observed for onshore turbines as designs are largely the same, but on a larger scale. Offshore foundations vary considerably, however, so the 4C offshore database [19] and various studies were used to estimate the material compositions of foundations based on the type of foundation and sea depth. The material quantities at each site were then calculated by multiplying the quantities per turbine by the number of turbines installed at each respective site. Operational life of 20 years was assumed as a conservative estimate, which has been used in conjunction with the date of commissioning to estimate the year in which each wind farm will be decommissioned and when the corresponding waste can be expected. Part replacement figures were also estimated and factored into the final waste calculations, the importance of which was highlighted by Andersen [27] and Andersen et al. [28]. It has been assumed, on average, this waste is generated half way through the operational life, so 10 years after commissioning.

\section{End of life scenarios}

To form the basis of the scenario-based assessment, the current practice end of life waste management procedures have been researched for each of the materials assessed within this study. Further research was then conducted to explore alternative waste management practices that represent improvements upon the current practice through movement up the waste hierarchy, toward more favourable outcomes. Andersen [27] and Andersen et al. [28] modelled three scenarios based on second-hand use of components and found a significant reduction in waste when $50 \%$ of turbine materials are re-used. This study builds upon these scenarios by exploring the environmental benefits that could be achieved through reuse, remanufacturing, recycling, and heat recovery from incineration of various components of a wind turbine. The waste calculations performed within this study formed the basis from which these benefits have been quantified. Six scenarios have been used to demonstrate the benefits that could be realised through implementation of various waste management procedures. Such benefits include reduction of waste, particularly to landfill, and GHG emissions savings. The scenario-based assessments were developed to demonstrate the importance of future investment in improved waste management procedures.

\section{Wind turbine materials}

Wind turbines can be broken down into four main components: foundation, tower, nacelle and rotor [28]. Martínez et al. [29] performed a LCA of a $2 \mathrm{MW}$ onshore wind turbine, producing the following inventory for each component:

- Foundation-mainly concrete, with some iron and steel.

- Tower-entirely steel.

- Nacelle-mainly iron and steel, with some copper and silica for electronic components and fibre glass and resin for the nacelle cover. 


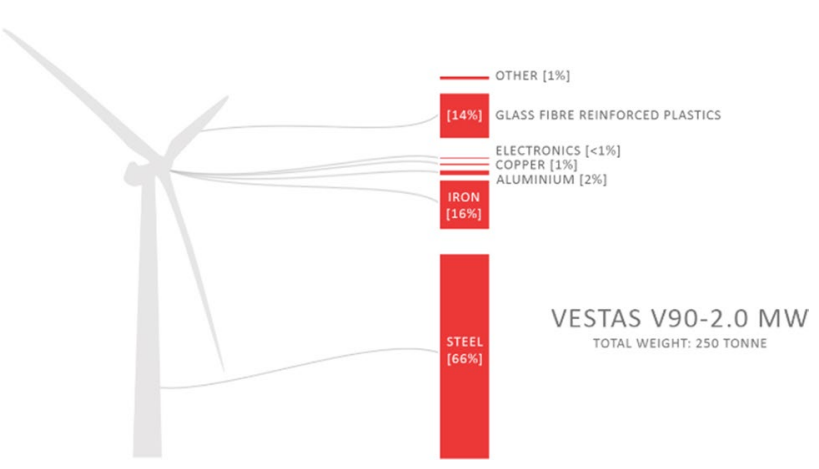

Fig. 1 Diagram demonstrating the material composition of a Vestas V90-2.0 MW wind turbine. (adapted from Andersen [27] and Andersen et al. [28] with permission)

- Rotor-cast iron for the blade hub, with the nose cone and blades consisting of glass reinforced plastic (GRP) and resin.

A LCA of two $2 \mathrm{MW}$ onshore wind turbine models by Haapala and Prempreeda [21] and a report prepared by PERI [30] and Zimmermann et al. [31] described similar inventories for material flows resulting from large scale deployment of wind energy. Steel and concrete were both reported to be the major components of the foundation, steel the main component of the tower, and the components of the nacelle were similar, with the addition of aluminium. The biggest variation between the three studies was the composition of the rotor blades, with the inclusion of carbon fibre reinforced plastics (CFRP) in some models by Haapala and Prempreeda [21] and PERI [30]. Most rotor blades are made from GRP [29]. However, as rotor sizes increase, stronger and more lightweight materials are required, leading to increased CFRP use despite its higher cost [30]. Zimmermann et al.
[31] and an Aerospace Engineering blog [33] describes hybrid GRP and CFRP composite designs as a common compromise between cost and strength. Figure 1 further demonstrates these findings.

Figure 1 demonstrates the material breakdown of a Vestas V90-2.0 MW wind turbine. It should be noted that while similar, the figures reported here are specific to this turbine model and are different to the figures used for the waste calculations performed within this study. For offshore developments, onshore wind turbine designs have been adapted for the marine environment, with stronger towers, pressurised nacelles, and material coatings to protect against wave pressures, sea spray, and salt corrosion [15, 30-34]. However, the main adaptations for offshore turbines are the foundations: there are numerous variations being developed to overcome the challenges associated with different surface conditions and seabed structures [35-37]. Monopile foundations are the most commonly used foundations as they are the cheapest and easiest to construct [35-37]. However, Kaiser and Snyder [37] reported a predicted increase in the use of other designs due to the depth restrictions associated with monopile foundations. Generally, offshore turbines use much less concrete (usually none) due to their foundation designs and use more bulk metals when compared with onshore developments [32].

Figure 2, adapted from the Society of Underwater Technology [38], displays the four offshore foundation types installed around the UK. Although sea depth largely influences the design reference of offshore foundations, as demonstrated within Fig. 2, seabed conditions are also a key factor [38, 39]. Although many existing studies calculate the materials used, and, therefore, waste generated, by specific models, there is no clear attempt to calculate the total levels of waste expected across the UK. This study has done so to inform the implementation of suitable waste management measures.

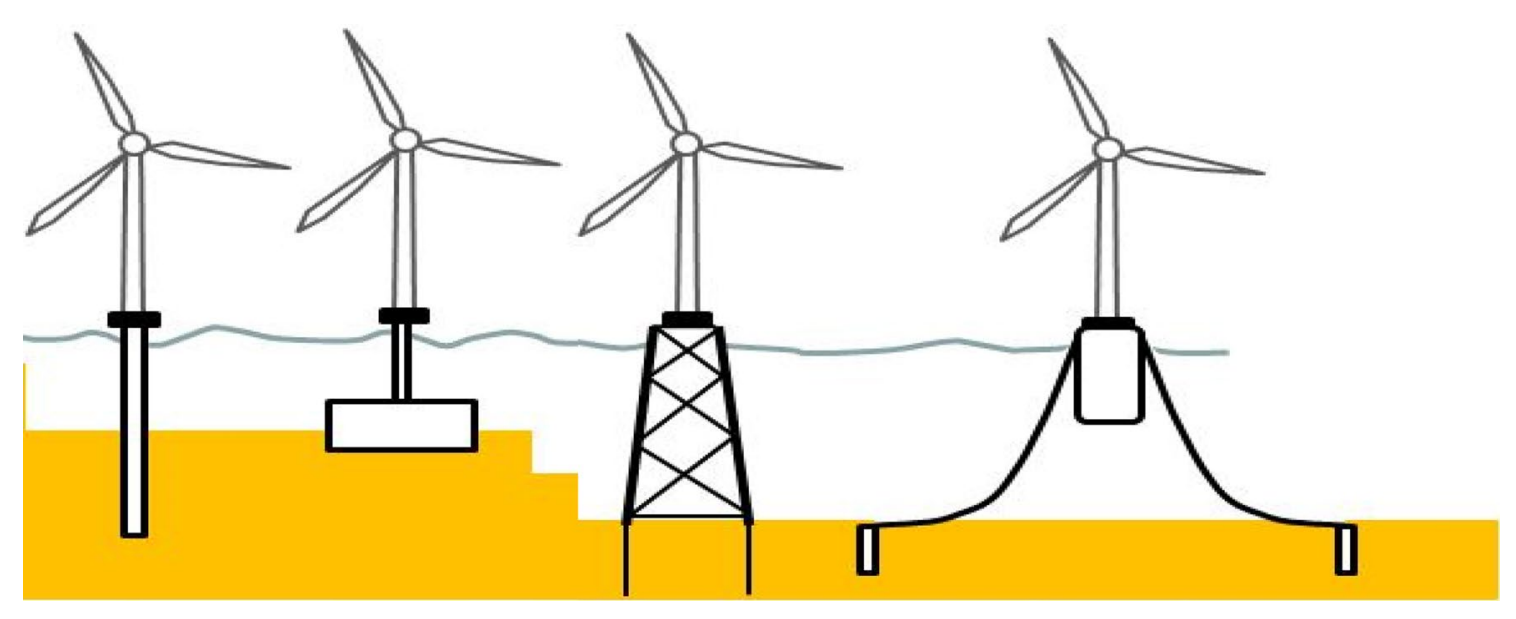

Fig. 2 Diagram displaying the four offshore foundation types installed around the UK. From left to right: monopile, gravity-based, jacket, and floating spar. (Adapted from the Society of Underwater Technology [38] with permission) 


\section{Recycling}

The EoL disposal scenarios outlined by several LCAs assumed the metals within wind turbines are currently recycled with a recovery rate of $90 \%$. However, though this a conservative estimate and recovery rates are often higher $[27,28,33,39,40]$. For GRP, Martínez et al. [29] and Vestas [35] assume incineration with heat recovery, while Properzi and Herk-hansen [40] assumed waste to landfill. Concrete is assumed to be left in the ground on site and is, therefore, classified as landfilled [21]. Building upon these findings, further research has been conducted regarding specific waste management procedures within the UK to generate a current practice baseline scenario. Using the EU waste hierarchy, this project will assess which components could be moved up the hierarchy based on current and future waste management methods. The EU waste hierarchy, from most to least favourable, is as follows from DEFRA [41]:

- Prevention

- Re-use

- Recycling

- Other recovery (such as heat recovery)

- Disposal

Specific options for improving waste management processes. Calculating expected waste will provide the waste management industry with future capacity requirements, facilitating informed investment decisions, while also providing a basis for the scenario-based assessment.

\section{Methodology and data analytics}

Due to the nature of this research project and the limited sources of readily available data for wind turbine decommissioning in the UK, the research was largely qualitative. While the case studies were rigorously analysed and validated, the results are limited to the case study sample size. Other limitations to this study include the sample size and sample bias for the research limited to the number of wind energy farms analysed in the UK, not taking into account future approved planning for the development of additional wind energy sources and providers. Access to the data has been challenging with a few companies. While there is historical data pertaining to material use, material quality, and specifications for the lifecycle of wind turbines, there is a lack of data analytics and consistent measurements for waste generation and the subsequent carbon footprint in the industry. As a result, the fundamentals of waste generation from wind power identified by the research are based currently on existing practices across the relevant UK industries.

The empirical regressions of engineering parameters of the wind turbines including the material composition specifications, capacities, decommissioned capacities, sizes, scaling effects, and materials flows were adapted from the previous works of Cao et al. [42]. Information was extracted from several databases such as the UKWED [25]; The Wind Power [26]; Wind Power Offshore [43]; 4C Offshore, 2018 [19] and combined with literature surveys internet were used to develop a novel database. This database contains information on all major operational wind power projects in the UK (as of September 2019), including 1575 onshore wind projects and 37 offshore projects. Table 1 provides an extract from this database, demonstrating the information contained.

This extract is taken from the 'Offshore' sheet of the database to demonstrate the additional 'Foundation Type' and 'Sea Depth' columns, highlighted. These are not present in 'Onshore' equivalent as the foundation material data were included within the LCAs of onshore turbines, so an additional calculation was not required. The calculations used to model the material compositions and weights of offshore foundations.

The foundation type and sea depth information were obtained from the 4C Offshore database [19]. There were two different sea depth ranges available for each wind farm-one from chart data, and the other from manufacturer reports. For this study, the depth range reported by the manufacturer was used. It was assumed that although

Table 1 Extract from the database developed for this study

\begin{tabular}{|c|c|c|c|c|c|c|c|}
\hline Site & No. of turbines & $\begin{array}{l}\text { Year com- } \\
\text { missioned }\end{array}$ & Manufacturer & Model & $\begin{array}{l}\text { Turbine capacity } \\
\text { (MW) }\end{array}$ & Foundation type & $\begin{array}{l}\text { Sea depth } \\
\text { (m) }\end{array}$ \\
\hline London Array Phase I & 175 & 2013 & Siemens & $3.6-107$ & 3.6 & Monopile & 12.5 \\
\hline $\begin{array}{l}\text { Gwynt Y } \\
\text { Mor }\end{array}$ & 160 & 2015 & Siemens & $3.6-107$ & 3.6 & Monopile & 20 \\
\hline Greater Gabbard & 140 & 2012 & Siemens & $3.6-107$ & 3.6 & Monopile & 26 \\
\hline Rampion & 116 & 2018 & Vestas & V112/3450 & 3.45 & Monopile & 29.5 \\
\hline West of Duddon Sands & 108 & 2014 & Siemens & $3.6-120$ & 3.6 & Monopile & 20.5 \\
\hline Thanet & 100 & 2010 & Vestas & V90/3000 & 3 & Monopile & 22.5 \\
\hline
\end{tabular}


the sea may be shallower or deeper than the manufacturers have reported in areas around the wind farm, the manufacturer will know the precise locations of each turbine and will have accurately measured the depth during the planning and installation process. An average of the maximum and minimum depth was taken and assumed for all turbines at that site in the absence of more detailed information.

\section{Analysis of life cycle assessments}

Twelve LCAs were analysed to determine the material compositions of 26 onshore wind turbines of various capacities. All the LCAs reported the quantities of steel, copper, aluminium, iron, plastic, and concrete within the turbine being assessed. The epoxy, resin, and overall composite materials, however, were reported individually in some LCAs, but categorised together in others. These have all been categorised together in this study and will hereby be referred to as 'composite materials'. Composite materials are generally found within the blades; however, it should be clarified that some can also be found within the nacelle. An attempt was made to ensure the most common turbine models were assessed to increase the accuracy of this study by ensuring the designs favoured by the most common manufacturers were represented within the data. The prevalence of each model within over $50 \%$ of the onshore wind turbines in the UK was calculated and Siemens was found to be the most common manufacturer, followed by Vestas. Vestas turbines are well represented throughout the LCAs used for this study, but no LCAs assessing Siemens turbines could be found. This could be due to a lack of such information in their turbine data specification sheets [35]. Also, Vestas have performed their LCAs for some of their models, whereas Siemens have not.

\section{Onshore wind turbine weight calculations}

The various weights of each material were plotted against the respective capacity of each turbine assessed to form a trend line. The intention was to use the equation of the trend line to estimate the weight of each of the materials within a turbine of any given capacity. This was performed for some of the materials, but for others, the trend line was not strong enough. The later sections of this article describe those with high $R$-squared values (concrete, composite materials, and steel or iron), and for those systems with low $R$-squared values (copper, aluminium, and plastic).

\section{Steel, iron, concrete and composite materials}

Graphs demonstrating the relationship between turbine capacity and the weight of steel or iron, concrete and composite materials are displayed in Figs. 3, 4, and 5.

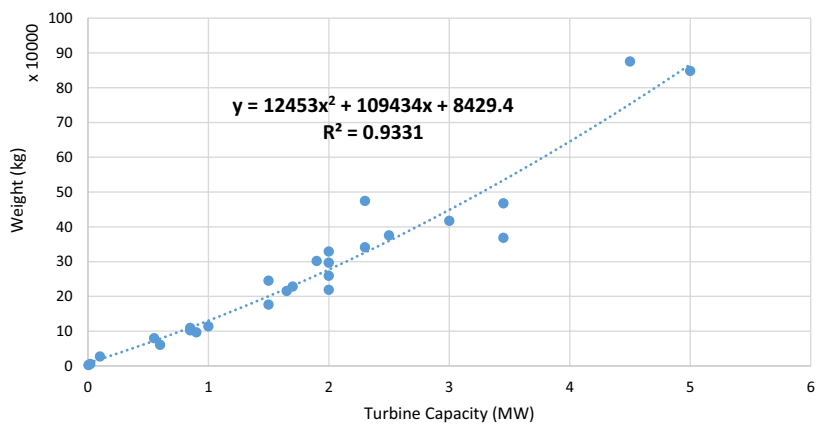

Fig. 3 Graph displaying the relationship between steel or iron weight and turbine capacity

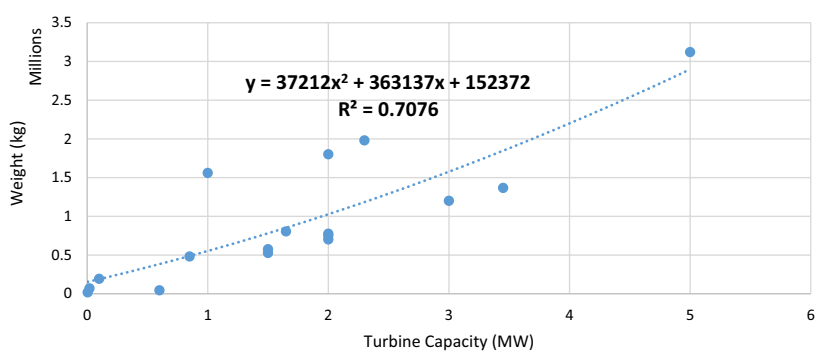

Fig. 4 Graph displaying the relationship between concrete weight and turbine capacity

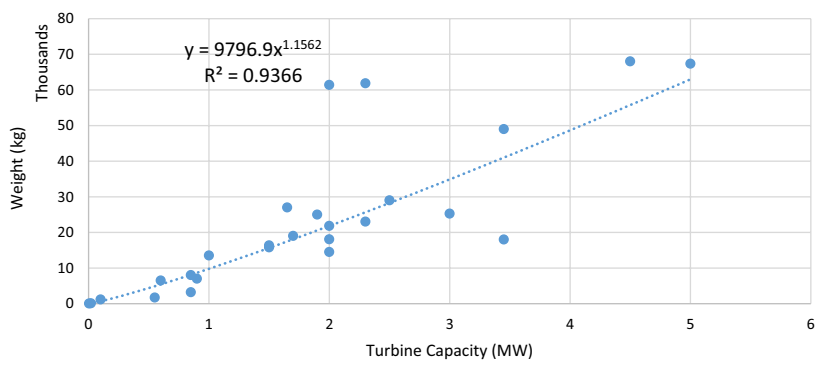

Fig. 5 Graph displaying the relationship between composite material weight and turbine capacity

The trend lines for steel or iron, concrete and composite materials had high $R$-squared values, each above 0.7 , demonstrating a good fit to the data (see Figs. 3, 4, and 5). For these materials, the trend line equations were used to calculate the weight of each material expected within turbines of any given capacity. These equations have been applied to each wind farm to calculate the material quantities for individual wind turbines, and then multiplied by the total number of turbines at each site to give a site total weight. The equations to calculate overall site weight for concrete, composite materials, and steel or iron are displayed below.

Equation (1): Calculating steel or iron waste expected from an onshore wind farm based on turbine capacity: 
$w=\left(12453 \times c^{2}+109434 \times c+8429.4\right) \times t$,

where: $w$ weight, $c$ single turbine capacity, $t=$ number of turbines.

Equation (2): Calculating concrete waste expected from an onshore wind farm based on turbine capacity:

$w=\left(37212 \times c^{2}+363137 \times c+152372\right) \times t$,

where: $w$ weight, $c$ single turbine capacity, $t$ number of turbines.

Equation (3): Calculating composite material waste expected from an onshore wind farm based on turbine capacity:

$w=\left(9796.9 \times c^{1.1562}\right) \times t$

where: $w$ weight, $c$ single turbine capacity, $t$ number of turbines.

The material compositions of turbines assessed within a study by Andersen [27] and Andersen et al. [28] (one of the 12 key LCAs analysed in this study) did not include materials within the foundations - only the towers, nacelles, blades, and hubs were included. Onshore turbine foundations contain steel or iron, meaning that the steel or iron quantities reported by Andersen [27] and Andersen et al. [28] were not fully representative of the quantity within the overall structure. Andersen [27] and Andersen et al. [28] found that the material compositions of 12 turbines of various capacities, which represented a significant proportion of those analysed within this study. Three of these 12 turbines were assessed within other LCAs, in which case the more detailed assessments were used instead. Assessments of nine turbines without foundation data remained, which still represented a significant proportion of the overall sample. Leaving these out of the steel or iron calculations would have reduced the accuracy of the resulting trend line, and therefore, the accuracy of the resulting steel or iron quantity estimations. To resolve this issue, the weight of the turbines (excluding foundations) reported by Andersen [27] and Andersen et al. [28] were used in conjunction with the more detailed material compositions reported within the remaining LCAs to estimate expected steel or iron quantities within the foundations. These were then added to the steel or iron figures stated by Andersen [27] and Andersen et al. [28] to ensure the steel or iron quantities were more accurate and representative of the overall structure.

To estimate the quantity of steel or iron within the foundations, firstly the foundation weights were calculated as a percentage of the overall weights of each structure for all turbines, where foundation data were reported. There was no apparent correlation between this figure and turbine capacity, so an average was taken and assumed regardless of capacity. This average was then applied to the total weights of the turbines to estimate their foundation weight $[27,43]$. The LCAs containing foundation data were then analysed again, this time to calculate the weight of steel or iron within the foundations as a percentage of total foundation weight. Again, there was no apparent correlation between these figures and turbine capacity, so an average was taken and assumed for all turbines. The average steel or iron content calculated was $4 \%$. This average was then used in conjunction with the estimated foundation weights calculated above to provide an estimation of steel or iron within each of the foundations. Adding these foundation steel or iron quantities to the steel or iron quantities reported by Andersen [27] and Andersen et al. [28] ensured the total quantities were now fully representative of the overall turbine structures.

Although these estimations will not be entirely accurate, most of the steel or iron within a wind turbine is not within the foundation, but in the tower, nacelle, blades, and hub. Therefore, any inaccuracies within these estimations will not be hugely significant in the context of the overall quantity of steel or iron per turbine. Moreover, undertaking the above calculations and allowing these additional nine samples to be used to model steel or iron quantities will have likely improved the accuracy of the results by significantly increasing the sample size (from 17 to 26). For concrete, however, which was also excluded from the study by Andersen [27] and Andersen et al. [28] the estimations calculated above would have represented $100 \%$ of the concrete within the structure. With foundations making up 79.4\% of the overall turbine structure on average, and without any additional reliable data to decrease the significance of errors, such estimations would be considerably inaccurate. It was decided that the negative impacts of any inaccuracies within the estimations were not outweighed by the accuracy improvements to be gained by increasing the sample size. These samples were, therefore, excluded from the sample for modelling concrete quantities.

\section{Copper, aluminium and plastic}

Graphs demonstrating the relationship between turbine capacity and the weight of copper, aluminium and plastic are displayed below.

As demonstrated by Figs. 6, 7, and 8, the $R$-squared values for the trend lines for copper, aluminium, and plastic were not as high as those for concrete, composite materials, and steel or iron. This could be due to variations in designs between manufacturers. For example, there were numerous turbines of various sizes containing no plastic or aluminium, presumably as it is possible to substitute these with other materials. Because these trend lines were weaker, another approach was needed to estimate the quantities of these 


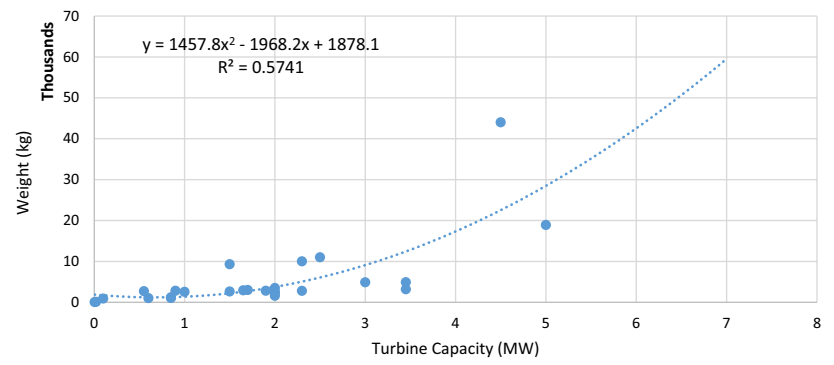

Fig. 6 Graph displaying the relationship between copper weight and turbine capacity

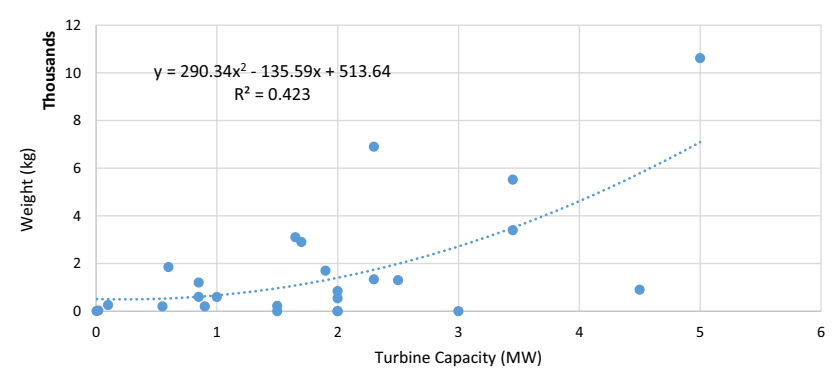

Fig. 7 Graph displaying the relationship between aluminium weight and turbine capacity

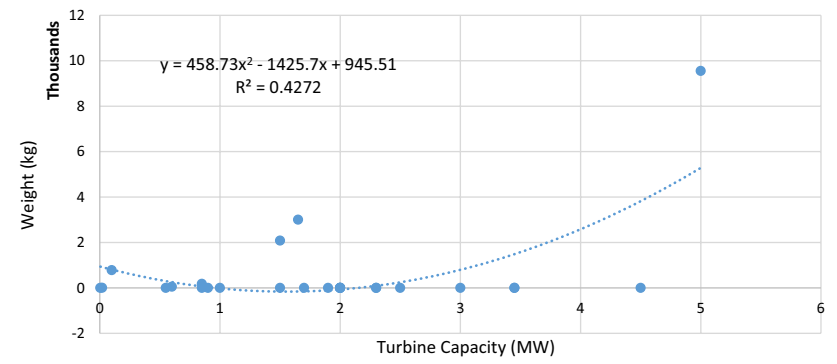

Fig. 8 Graph displaying the relationship between plastic weight and turbine capacity

materials within any given turbine. To overcome this issue, 'small', 'medium' or 'large' size categories were applied to the turbines assessed within the LCAs. The turbines ranged from $5 \mathrm{~kW}$ to $5 \mathrm{MW}$ and were sorted into the following categories:

- Small-<1 MW

- Medium- $\geq 1 \mathrm{MW}$ and $<3 \mathrm{MW}$

- Large- $\geq 3 \mathrm{MW}$

The average weight of copper, aluminium, and plastic were calculated for each size category. The results are displayed in Table 2.
This method of size categorisation builds upon a similar method demonstrated by Liu and Barlow [44]. This method is less accurate than extrapolating from strong trend lines (as described above) due to the possibility of turbines within a certain category being 'polarised' towards one end of that category. Using weak trend lines, however, would have been less accurate still. This method does represent the slight positive correlation between weight and capacity, which is not represented by the best fitting trend line for plastic. The trend line for plastic suggests more plastic within $0.1 \mathrm{MW}$ turbines than there is in $2.3 \mathrm{MW}$ turbines which seems unlikely, and negative plastic quantities in 1.5 MW turbines, which is not possible. To calculate the total estimated weight of each material at any given wind farm, the weight figure corresponding to the capacity of turbine installed at a site was multiplied by the number of those turbines installed.

\section{Offshore turbines weight calculations}

There are too few LCAs assessing offshore wind turbines within the literature to have applied the same method as described above for onshore turbines as the sample size would have been too small for accurate modelling. There is also a variety of foundation types installed offshore in the UK, so different methods were required to account for these variations. The offshore material composition calculations were split into two sections: 'tower, nacelle, blades and hub', and 'foundations'. These methodologies are described in this section. The calculated results of total input and materials for wind energy systems with thousand-ton consumption rates followed similar studies of Kim et al. [24]

\section{Tower, nacelle, blades and hub}

Offshore turbine designs, excluding foundations, are similar to those for onshore. Therefore, the material compositions are likely very similar, just on a larger scale in some cases. Based on this assumption, material compositions as a percentage of overall turbine weight were calculated from the onshore turbine LCA data discussed above. Offshore turbine weights were then researched, and onshore material composition proportions were assumed and applied. The material compositions of onshore turbines were calculated

Table 2 Table displaying the average weight of copper, aluminium, and plastic for each size category

\begin{tabular}{lclc}
\hline Size & Copper $(\mathrm{kg})$ & Aluminium $(\mathrm{kg})$ & Plastic $(\mathrm{kg})$ \\
\hline Small & 1220 & 543 & 127 \\
Medium & 4374 & 1495 & 391 \\
Large & 15,168 & 4086 & 1910 \\
\hline
\end{tabular}




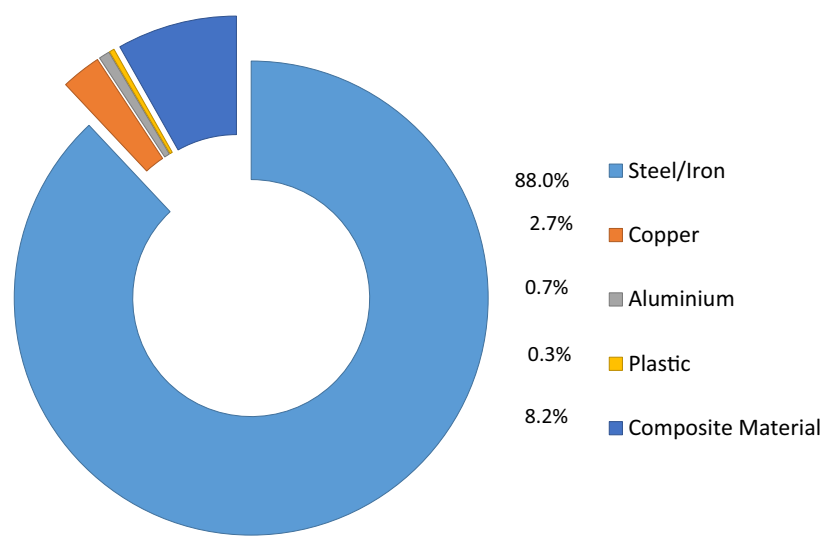

Fig. 9 Chart displaying the average material composition of a 'large' onshore wind turbine

for each size category (small, medium, and large, as above) to see whether there were any patterns regarding turbine capacity and differences in proportions of the materials. There were slight variations between size categories, but no linear trend. The proportions calculated for the 'large' onshore turbine category were, therefore, applied to offshore turbines as the turbines within this category are closest in size to the average size of offshore turbines installed around the UK. These material proportions assumed are displayed in Fig. 9.

For the research of the weights of the various offshore turbine models assessed within this study, an attempt was made to research each site individually to maximise accuracy. However, this was not possible for some sites. In these cases, assumptions have been made based on information available and patterns observed. If there was no information available regarding turbine weights at a certain site, but the same model was installed elsewhere and the data were available for that site, the same weight was assumed. Tower heights can vary between sites with the same models; however, so these assumptions may have added inaccuracies. Where data had been available for many of the individual sites, often the turbine weights were broken down by each main component (e.g., tower, nacelle, blades, and hub). For sites with no turbine weight data available, and no information available for the same model elsewhere, these component weights were used to make assumptions. For example, tower, nacelle, and hub weight data were assumed based on information available for turbines of the same capacity, where available. If these data were not available for turbines of the same capacity, the weight data from the turbine closest in capacity were assumed. For assumptions regarding the weight of blades, blade length data were used to find the closest match within the data available, and therefore, the most accurate assumption. Where blade length data were not available, blade weights of turbines of the same, or most similar, capacity were assumed, as was performed for the tower, nacelle, and hub. These component weights were then totalled, and the material composition proportions of 'large' onshore turbines were applied, as discussed above.

\section{Foundations}

The following four foundation types are installed offshore across the UK:

- Monopile

- Jacket

- Gravity-based

- Floating spar

Monopile foundations are the most prevalent of the foundation structures in the UK, having been utilised at 31 of the 37 sites. Jacket foundations are the second most prevalent having been installed at 4 of the 37 sites, while gravity-based and floating spar foundations are only installed at one site each. All are made almost entirely from steel, except gravitybased foundations which contain both steel and concrete [42, 44-46]

\section{Monopile}

Kiełkiewicz et al. [47], demonstrated a pattern between monopile foundation weight and sea depth for 3.3 MW and $8 \mathrm{MW}$ turbines. These patterns have been applied to the relevant offshore wind farms within this study to estimate monopile foundation weights. Using the original data used in the study by Kiełkiewicz et al. [47], an average of the corresponding figures for each of the two turbine sizes was calculated to produce expected data for a turbine of around 5.65 MW. 'Small', 'medium' and 'large' size categories ( $<4.5 \mathrm{MW}, 4.5-6.5 \mathrm{MW}$, and $>6.5 \mathrm{MW}$, respectively) were then created around these three turbine sizes. The trend observed for the $3.3 \mathrm{MW}$ turbine was assumed for all turbines within the 'small' category, while the trend generated for the 'average' turbine of around 5.65 MW and the trend observed for the $8 \mathrm{MW}$ turbine was applied to the 'medium' and 'large' categories, respectively. Figure 10 displays the three trend lines used.

The average sea depth at each site was then used in conjunction with the corresponding trend line equation, based on the capacity of turbines installed there, to predict the average monopile foundation weight per turbine. This figure was then multiplied by the number of turbines installed to calculate the total quantity of steel within the foundations at each site. The calculations for each of the size categories are displayed below. 
Equation (4): Calculating the average weight of monopile foundations for an offshore wind farm with 'large' wind turbines installed:

$w=\left(67.752 \times d^{3}-5270.1 \times d^{2}+161737 \times d-635636\right) \times t$,

where: $w$ overall foundation weight, $d$ average sea depth, $t$ number of turbines.

Equation (5): Calculating the average weight of monopile foundations for an offshore wind farm with 'medium' wind turbines installed:

$w=53.311 \times d^{3}-3730.4 \times d^{2}+108771 \times d-309429$,

where: $w$ overall foundation weight, $d$ average sea depth, $t$ number of turbines.

Equation (6): Calculating the average weight of monopile foundations for an offshore wind farm with 'small' wind turbines installed:

$w=58.904 \times d^{3}-3764.8 \times d^{2}+94756 \times d-284745,(6)$

where: $w$ overall foundation weight, $d$ average sea depth, $t$ number of turbines.

\section{Jacket}

To calculate the weight of jacket foundations, patterns observed by Hensel et al. [39] were applied. Within this study, upper and lower bounds are reported for jacket foundation weights at various depths, and two corresponding trend lines are formed. The equations of these two trend lines have been applied to the average sea depth at each site with jacket foundations installed. The upper and lower bounds created for each site were then averaged and this weight was assumed for the jacket structure per turbine installed. Hensel et al. [39] also reported the weights of transition pieces and anchoring piles, which make up part of the jacket foundation structure, but which were not included in the above calculations. The weight of a transition piece was reported not to vary with depth and was assumed by Hensel et al. [39] to weigh 160 tonnes. Hensel et al. [39] also demonstrated that the weight of foundation piles varied based on seabed properties, but not significantly based on sea depth. As information regarding seabed properties was unavailable for the relevant sites within this study, an average was taken of the upper and lower bounds and applied to all jacket foundations. The range reported by Hensel et al. [39] was 250-500 $\mathrm{t}$, and the average assumed and applied within this study was, therefore, 375 tonnes. The corresponding results of the above calculations were added together and multiplied by the number of turbines at each site to calculate the overall weight of steel within the foundations. The equations used to calculate the overall foundations weights for each of the four relevant sites are displayed below.

Equation (7): Calculating the upper bound for jacket structure weight (excluding transition piece and piles):

$u=0.149 \times d^{2}-5.342 \times d+342.299$,

where: $u$ upper bound for jacket structure weight (excluding transition piece and piles), $d$ average sea depth.

Equation (8): Calculating the lower bound for jacket structure weight (excluding transition piece and piles):

$l=0.034 \times d^{2}-3.611 \times d+80.009$,

where: $l$ lower bound for jacket structure weight (excluding transition piece and piles), $d$ average sea depth.

Equation (9): Calculating the average overall weight of jacket foundations at an offshore wind farm:

$\left(\left(\frac{u+l}{2}\right)+160+375\right) \times t$

where: $u$ upper bound for jacket structure weight (excluding transition piece and piles), $l$ lower bound for jacket structure weight (excluding transition piece and piles), $t$ Number of turbines.

\section{Gravity-based and floating spar}

As there was only one site with each of these foundation types, it was possible to research each site on an individual basis. A report and presentation by BAM Nuttall [45] contained the material compositions and weights of the gravity-based foundations installed at the Blyth Offshore Wind Demonstration Project (Phase 1). $1800 \mathrm{~m}^{3}$ of concrete was reportedly used within the shell of the foundation base, which equates to 4320 tonnes following application of the conversion factor of $2.4 \mathrm{t} / \mathrm{m}^{3}$ from the Inventory of Carbon and Energy (ICE) Database [48]. A further 7000 tonnes of ballast concrete was used to fill the foundation base shell before submersion. BAM Nuttall [45], also reported 500 tonnes of steel reinforcement within the foundation base shell, in addition to 660 tonnes of steel for the foundation shaft. The floating spar foundations installed at the Hywind Scotland Pilot Park consist of steel substructures (the floating spar aspects), chains, and suction anchor. Three suction anchors are used to attach the foundations to the seabed via three steel chains, each close to $900 \mathrm{~m}$ in length. The substructures contain 2300 tonnes of steel, while the steel chains weigh around 400 tonnes each, with the suction anchors weighing a further 300 tonnes each. Per turbine, this equates to 2300 tonnes of steel for the substructures, 1200 tonnes for the chains, and 900 tonnes for the suction anchors, totalling 4400 tonnes. 


\section{Waste generation over time}

The year of commissioning for each wind farm was used in conjunction with the waste data calculated above for onshore and offshore wind farms to facilitate the calculation of total quantities of waste expected within a given year or period. The 20-year operational lifetime assumed for wind turbines within this study was added to the year of commissioning for each wind farm to generate an expected year of decommissioning. The waste quantities of each material were then added up for all turbines decommissioned within the same year, resulting in the quantification of the total waste expected each year up to 2038 for each of the material categories. Although there will be an overall increase in expected waste generation over time, waste generation figures would fluctuate when presented by year due to commissioning patterns up to 2018. From a waste management perspective, 'smooth', average trend lines are much more useful as waste generated does not necessarily need to be processed the year it is produced. For example, waste produced in a year of above average decommissioning rates can be stockpiled and managed in years where decommissioning rates are below average. Investment in waste management facilities with the capacity to manage the waste generated in years of high decommissioning rates would, therefore, result in under-capacity operation during years of lower decommissioning rates. The results of this study have, therefore, been presented in 5-year intervals. This is further justified by variations in actual operational lifetimes of wind farms. Wind farms are not always decommissioned exactly 20 years after commissioning, resulting in inevitable inaccuracies in results presented by year. Although inaccuracies will still exist within the results presented by 5-year intervals, they will not be as significant, because fluctuations in decommissioning rates between years will average out.

The 5-year intervals used run from 1990-1994 to 2035-2039. However, the calculations performed only account for waste up to 2038 as reliable data are only available for turbines commissioned, and these data, therefore, do not exist beyond the year of this study (2018). Also, at the time of performing these calculations (October 2018), even turbine commissioning in 2018 was not fully accounted for. Waste expected from turbines commissioned between 2015 and September 2018 has, therefore, been prorated to ensure the 2035-2039 time period is sufficiently represented. Without doing so would result in significant underestimation of waste generation between 2035 and 2039. The waste expected between 2035 and October 2038 was divided by 3.75 to calculate the average waste quantity expected per year, then multiplied by 5 to give the expected quantity over the 5 -year period. The megawatt capacity installed, displayed alongside waste quantities were also prorated in this way for the 2035-2039 period.

\section{Wind turbine part replacement}

Once more, Andersen [27] and Andersen et al. [28] demonstrated the importance of accounting for the replacement of certain turbine components during a turbine's life cycle as these replacements amount to additional waste not otherwise considered. Certain components wear down or break entirely during the lifetime of a wind turbine due to the extreme pressures and forces they are faced with. According to Andersen [27] and Andersen et al. [28] the gear box, generator, and rotor blades are the most commonly replaced parts, with an average annual replacement rate of $3.1 \%$ for the gearbox, $2.9 \%$ for the generator, and $2.2 \%$ for each blade. Andersen [27] and Andersen et al. [28] also reports the average amount of copper, aluminium, composite material, and steel or iron within each of these components, as a percentage of overall component weight. These figures are presented in Table 3.
Fig. 10 Graph displaying the relationship between monopile foundation weight and sea depth for small, medium, and large offshore wind turbines

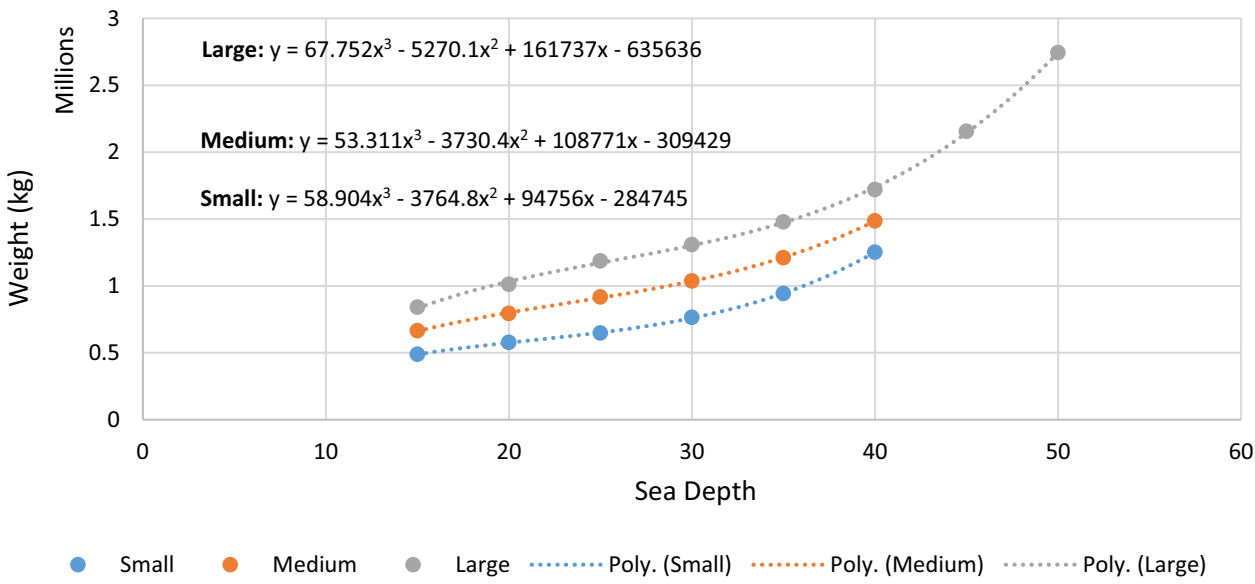


Material composition figures for each component were used in conjunction with estimated component weights for turbines of various capacities to calculate average material compositions in terms of weight. These figures were then multiplied by the corresponding part replacement rates to calculate the average amount of each material expected as waste annually, before being multiplied by 20 to calculate expected waste generated over a turbine's lifetime.

Estimated component weights were calculated for each of the size categories for onshore and offshore turbines, as used above, to increase accuracy. Various methods have been used to calculate estimated component weights for turbines of various capacities.

\section{Results and discussion}

As discussed in the methodology section, the waste expected over time as a result of wind turbine decommissioning in the UK was calculated separately for onshore and offshore wind farms. These data have also been combined to create an overall waste model. The results of the onshore, offshore, and overall waste calculations are presented in Figs. 11, 12, $13,14,15$ and 16 . The capacity commissioned during each period has been presented within these figures to demonstrate the clear relationship between installed capacity and waste generation, and the associated lag-time due to the operational lifetime assumed.

\section{Onshore wind turbines}

Figure 11 demonstrates that concrete accounts for the majority of onshore turbine waste, but this majority decreases from $84 \%$ of the waste expected for the 2010-2014 period to $77 \%$ of waste expected in 2035-2039. Steel or iron also makes up a relatively large proportion, accounting for $14 \%$ of waste expected in $2010-2014$, increasing to $21 \%$ by $2035-2039$. Although the remaining materials only make up a small proportion

Table 3 Average annual replacement rate and material breakdown of a wind turbine blade, generator and gearbox

\begin{tabular}{|c|c|c|c|c|c|}
\hline \multirow[t]{2}{*}{ Component } & \multirow{2}{*}{$\begin{array}{l}\text { Average } \\
\text { annual } \\
\text { replacement } \\
\text { rate }(\%)\end{array}$} & \multicolumn{4}{|c|}{$\begin{array}{l}\text { Material composition (\% of overall com- } \\
\text { ponent weight) }\end{array}$} \\
\hline & & $\begin{array}{l}\text { Steel or } \\
\text { iron }(\%)\end{array}$ & Copper & Aluminium & $\begin{array}{l}\text { Com- } \\
\text { posite } \\
\text { material }\end{array}$ \\
\hline Blade & 2.2 & 3 & - & $0.3 \%$ & $95 \%$ \\
\hline Generator & 2.9 & 79 & $21 \%$ & - & - \\
\hline Gearbox & 3.1 & 100 & _- & _- & - \\
\hline
\end{tabular}

of the total waste $(1.43 \%$ in $2010-2014$, increasing to $2.21 \%$ in $2035-2039$ ), the actual waste quantities are still significant, particularly by the 2030s. The waste quantities expected from composite materials, copper, aluminium and plastic only are presented in Fig. 12 to demonstrate these figures in greater detail.

Composite material makes up the largest proportion of waste when concrete and steel or iron are not included, making composite material the third most abundant waste material. Composite material accounted for $0.9 \%$ of expected overall onshore turbine waste for the 2010-2014 period, increasing to $1.6 \%$ by $2035-2039$. Copper is the next most abundant (around $0.3 \%-0.4 \%$ of overall waste), followed by aluminium (around $0.1 \%$ ), then plastic $(<0.05 \%)$.

\section{Offshore wind turbines}

Figure 13 displays the waste expected from offshore turbines over time, using the same 5-year intervals as above. Unlike onshore turbine waste, the vast majority of offshore turbine waste is steel or iron due to the steel used in most offshore foundations, rather than concrete onshore. Steel or iron accounts for $93 \%$ of overall waste expected from offshore turbine decommissioning for the 2020-2024 period, fluctuating somewhat during 2025-2029 and 2030-2034, but ultimately decreasing to $90 \%$ of total waste expected for 2035-2039. The waste quantities expected from the remaining materials (all excluding steel or iron) are presented in Fig. 14 to demonstrate these figures in greater detail.

Due to the absence of concrete in most offshore wind farm designs, composite material is generally the second most abundant waste material, accounting for 3.8\%-4.9\% of overall waste. The installation of five gravity-based foundations at the Blyth Offshore Wind Demonstration Project (Phase 1) in 2018, however, has resulted in concrete becoming the second most abundant waste material expected in 2035-2039. Concrete is expected to account for $4.8 \%$ of overall waste from offshore turbines in 2035-2039. This figure, however, is higher than the total weight expected from the five gravity-based foundations expected to be decommissioned during this period. This is because the waste figures for this 5-year interval were prorated as there was only data available for 3.75 of the 5 years within the 2015-2019 commissioning period and associated 2035-2039 decommissioning period.

Copper accounts for around $1.5 \%$ of the waste expected in 2020-2024, fluctuating somewhat between 2025 and 2034 , but decreasing overall to $1.3 \%$ of waste expected in 2035-2039. Aluminium accounts for around $0.4 \%$ in $2020-2025$, decreasing to $0.4 \%$ by $2035-2039$, while plastic accounts for around $0.2 \%$ of waste expected for all 5-year intervals. Figures 11, 12, 13, and 14 do not include waste 

power capacity commissioned and total waste expected from onshore turbine decommissioning over time
Fig. 11 Overall onshore wind
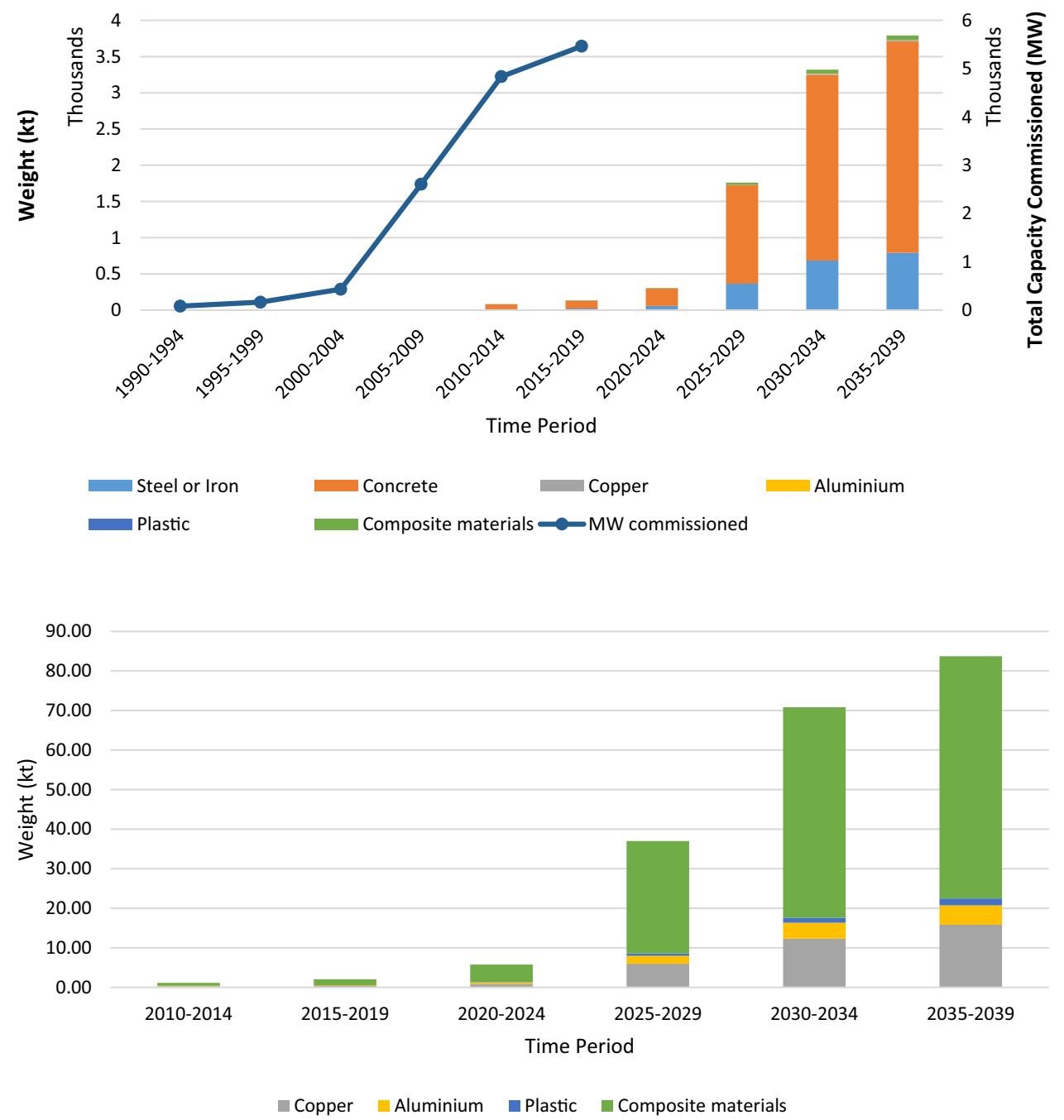

Fig. 12 Total waste expected from onshore turbine decommissioning over time, excluding concrete and steel or iron

Fig. 13 Overall offshore wind power capacity commissioned and total waste expected from offshore turbine decommissioning over time

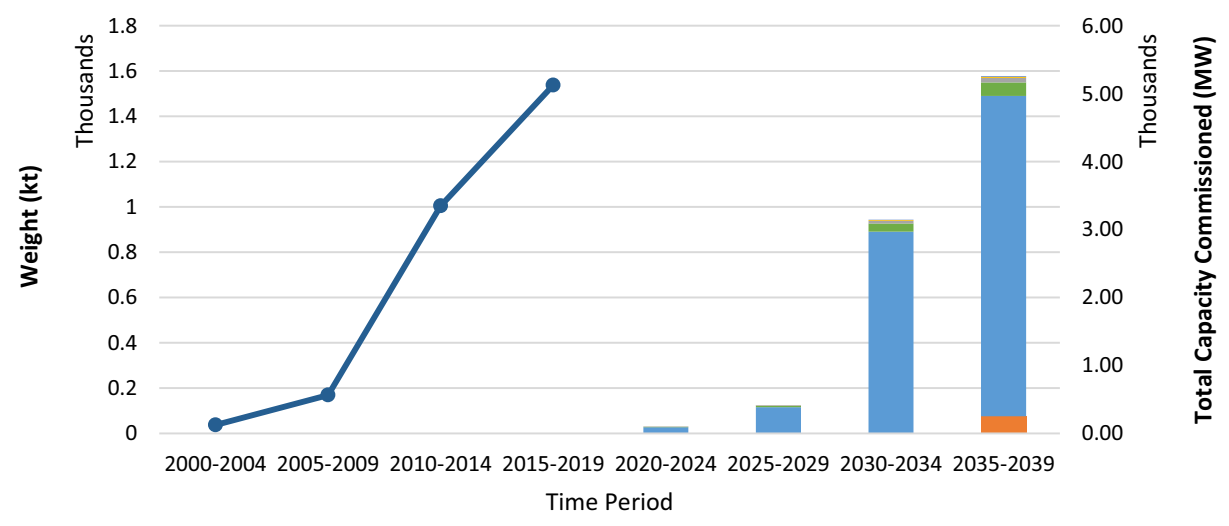

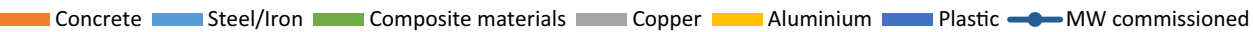

expected from part replacement as the part replacement forecast was conducted based on overall waste from onshore and offshore wind turbines. This forecast was conducted in this way to increase the sample size and, therefore, the accuracy of the calculations. Conducting separate part replacement forecasts for onshore and offshore resulted in different overall forecast figures when added together. These separate forecasts have, therefore, been excluded from this study for consistency and could, therefore, not be included above. Figure 15 presents the overall waste figures expected from both 
onshore and offshore wind turbine decommissioning in the UK, and also includes part replacement figures.

\section{Overall power capacity and total waste generation}

Steel or iron waste accounts for around $45 \%$ of overall waste for the two periods between 2000 and 2009, then decreases to $20 \%$ for 2010-2014, before increasing gradually back to $45 \%$ for 2035-2039. The high steel or iron proportion between 2000 and 2009 is because there is no concrete waste during this time as, based on the assumed 20-year operational lifetime of wind farms, no decommissioning was expected. The decommissioning waste was first accounted for within the 2010-2014 period, in which concrete accounted for $75 \%$ of waste. The proportion of concrete waste then decreases each subsequent period to $50 \%$ in 2020-2024, while the proportion of steel or iron increases to $38 \%$ over the same period. The proportion of concrete then increases to $63 \%$ for the $2025-2029$ period, which is matched by a decrease in steel to $32 \%$. This is explained by the rapid rise in onshore installation rates in 2005-2009, while a less dramatic rise is observed for offshore (see Figs. 11 and 13). A dramatic rise in offshore installation rates during the 2010-2014 period, however, and continued rise during 2015-2019, is then reflected by increases in the proportion of steel or iron waste to $45 \%$. The proportion of concrete waste decreases to $49 \%$ at this time. Although onshore installation rates also increased between 2010 and 2019, capacity installed during 2010-2014 and 2015-2019 was only $85 \%$ and $110 \%$ higher than capacity installed during 2005-2009, respectively. Offshore commissioning rates, however, saw dramatic increases of $493 \%$ and $808 \%$ during 2010-2014 and 2015-2019, respectively, compared to capacity installed in 2005-2009. The waste quantities of the remaining materials are displayed in Fig. 16, to demonstrate these figures in greater detail.

Composite materials account for $52 \%$ and $51 \%$ of total waste expected within the 2000-2004 and 2005-2009
Fig. 14 Total waste expected from offshore turbine decommissioning over time, excluding steel or iron

Fig. 15 Overall wind power capacity commissioned and total waste expected from turbine decommissioning and part replacement over time
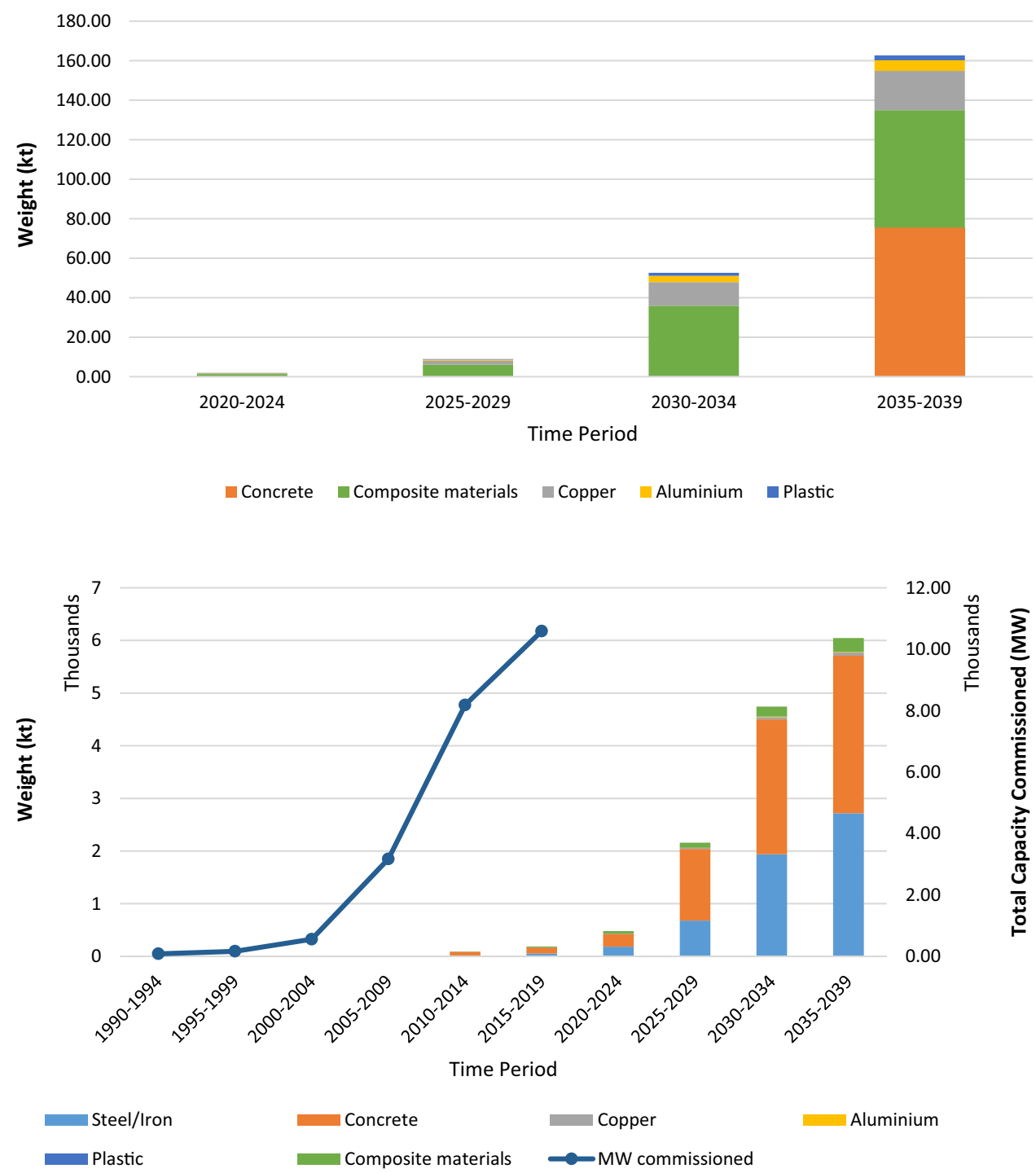
periods, respectively. This is because only waste from part replacement is expected during this period, of which composite materials account for a significant proportion. Following the generation of decommissioning waste from 2010 onwards, the proportion of composite material waste decreases to $4 \%$ of total waste for 2010-2014. This figure then fluctuates between $4 \%$ and $10 \%$ for the subsequent periods up to 2039. These fluctuations are not as easily explained as those observed for concrete and steel or iron, as described above. This could be because this relationship between concrete and steel or iron is explained by one material being replaced by the other to a certain extent, depending on foundation design, whereas blade weight variations do not necessarily share such a relationship with other materials. For example, two offshore turbines of similar capacities, with the same blade weights but at different sea depths, would have the same blade weight mass, but significantly different overall weights. The blade weight as a proportion of overall weight would, therefore, be lower for turbines with heavier foundations. Fluctuations in the proportion of blade weight over time could, therefore, be explained by the preferred turbine design patterns, whereby offshore turbine installation has increased over time and a variety offshore foundation types have been developed. Copper accounts for around $2.5 \%$ of total waste between 2000 and 2009 due to the requirement for copper for part replacement. The proportion of copper then decreases to $0.7 \%$ for the 2010-2014 period, before then fluctuating over time but increasing overall to around $1 \%$ in 2025-2039. As aluminium is also required for part replacement, aluminium waste is also expected between 2000 and 2009. The proportion of aluminium is expected to be around $0.16 \%$ over this period. This proportion then decreases to $0.12 \%$ by $2015-2019$, before gradually increasing over time to $0.18 \%$ in $2035-2039$. There is no plastic waste associated with the replacement of components considered within this study, so no waste is expected between
2000 and 2009. Plastic accounts for $0.03 \%$ of overall waste in 2010-2014, which increases over time to $0.07 \%$ of overall waste in 2035-2039.

\section{End of life wind turbines-current practice in the UK}

This section assesses current UK practices regarding the end of life waste management processes for each of the materials identified in this study. The findings have been used to inform the development of a baseline scenario for each material, as was demonstrated within LCAs conducted by Haapala and Prempreeda [21], Martínez et al. [29], Vestas [35], Chipindula et al. [49], and Tazi et al. [50]. A scientific attempt has been made to ensure the baseline scenarios are as accurate as possible regarding specificity to the UK and the specific applications of these materials within wind turbines, while also aligning with the literature as much as is reasonably possible.

\section{Steel or iron}

As steel is an alloy of iron and both are ferrous metals, both metals are treated within the same recycling chain [47-49]. Steel and iron are infinitely recyclable and are easy to recover as both materials are magnetic [50]. Although, due to the addition of other elements depending on intended use, and impurities added during the scrapping and recycling processes, steel purity generally decreases each time it is recycled. These impurities can, however, be removed through further processing, although this can be a costly process. Numerous LCAs used within this study have assumed a $90 \%$ recycling rate for steel and iron, with a $10 \%$ loss [21, $27,33,47]$. Specifically, in relation to the UK steel recycling industry, Allwood [51] also reports these recycling rates and attributes the $10 \%$ loss to steel below the ground (such as steel within foundations), which is buried in situ
Fig. 16 Overall waste expected from turbine decommissioning and part replacement over time, excluding concrete and steel or iron

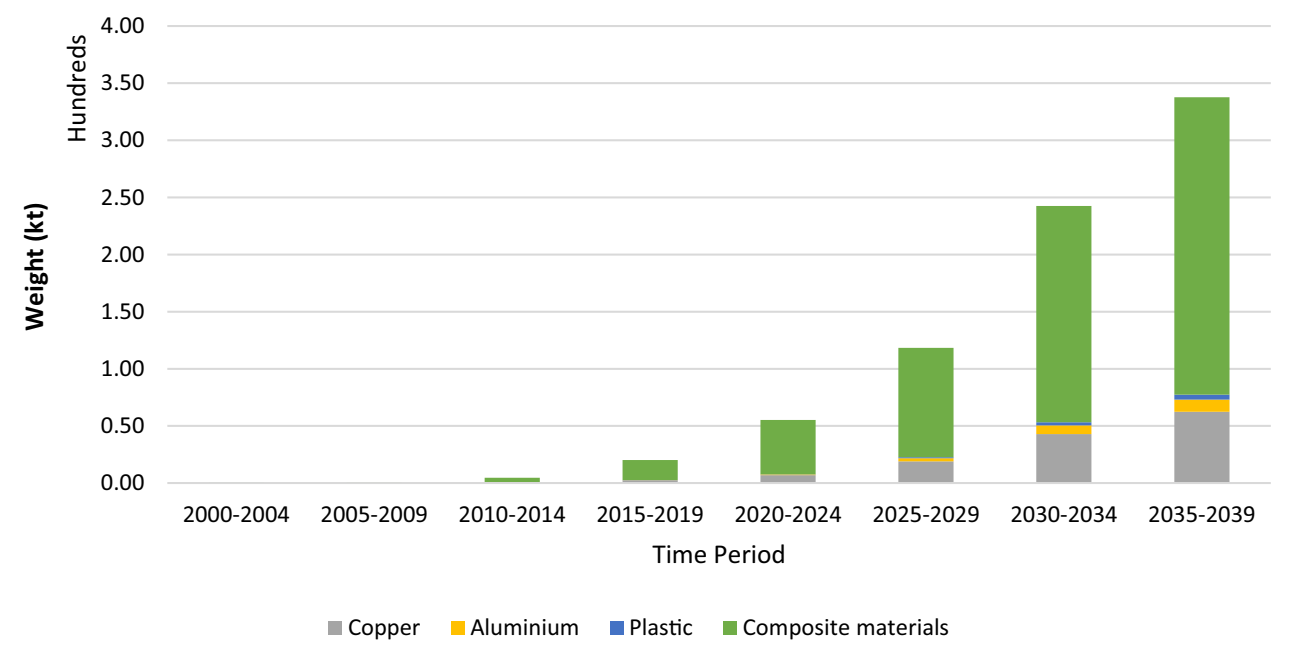


(landfilled). It should be noted, however, that the actual steel or iron quantity that is landfilled will be dependent on wind turbine foundation designs. This figure will, therefore, vary over time based on the mix of turbine designs decommissioned in a given year or period. Using data reported within the LCAs, the average quantity of steel or iron in onshore foundations was calculated. An average of $13 \%$ of the overall steel or iron content of onshore turbines was within the foundations. Therefore, steel or iron waste generated prior to the 2020-2025 period, before any waste is generated through offshore turbine decommissioning, will likely have a slightly lower recovery rate than the $90 \%$ assumed within the literature. Monopile foundations can extend 10-20 m below the seabed according to the Danish Wind Industry Association [54] and during decommissioning are cut off a few meters below the seabed [50-54]. Depending on sea depth, this could also result in a large proportion of the monopile foundation being landfilled, which could represent greater than $10 \%$ of the overall steel or iron weight. The piles of all piled foundations are cut off in this way, meaning jacket and floating spar foundations could also have significant proportions of their foundations landfilled [52].

As offshore turbines have become increasingly popular in the UK, it is possible for the proportion of recoverable steel or iron waste to change over time, possibly to below that observed for onshore turbines. Nonetheless, a recovery rate of $87 \%$, with $13 \%$ loss to landfill, is assumed for the baseline scenario within this study. Further modelling to accurately predict recovery rates for offshore turbines is not feasible within the scope of this study. The $87 \%$ assumed recovery rate also aligns relatively closely with the assumptions elsewhere within the literature.

\section{Concrete}

The LCAs performed by Haapala and Prempreeda [21] and Chipindula et al. [49] assume that $100 \%$ of concrete waste from turbine decommissioning is landfilled. Haapala and Prempreeda [21] attribute this to onshore foundations generally being left in the ground following turbine decommissioning. However, with the installation of gravity-based foundations offshore, the proportion of concrete landfilled may decrease in the future. RSK [55] reports that gravity-based foundations would be removed entirely during decommissioning. There is some debate around the complete removal of gravity-based foundations, however, as marine habitats will have developed around the large foundation bases by the end of the turbine's design life [44-47]. It is likely that removal of gravity-based foundations will depend largely upon the scale of habitat formation, species affected by foundation removal and whether leaving the foundation in situ will pose a navigational hazard. As most of the concrete waste generation is expected from onshore foundations and there is uncertainty around the decommissioning method for gravity-based foundations, $100 \%$ of concrete is assumed to be landfilled for baseline scenario within this study.

\section{Composite materials}

The main constituents of composite materials are CFRP and GRP, the recycling processes for which are much less well established than those for the other materials assessed within this study. Fibre reinforced plastics (FRPs) are inherently difficult to recycle as it is difficult to separate the reinforcement fibres from the polymer resins as stated by the Renewable Energy Focus report [56]. Alternative waste management processes are currently being developed, but landfilling remains the dominant option [55-58]. Landfill tax for FRP is a major driver of the development of new techniques [54], while Germany has banned FRP to landfill entirely. LCAs performed by Haapala and Prempreeda [21], Martínez et al. [29], Vestas [35], and Chipindula et al. [49] all assumed $100 \%$ of FRP waste is landfilled. Within the UK specifically, the landfill rate was reported as $98 \%$ by the University of Strathclyde [58]. As recycling and other waste management processes are in their infancy, it is unclear how the remaining $2 \%$ of FRP waste is being processed. Therefore, $100 \%$ landfilling has been assumed for the baseline scenario here as a worst-case scenario and for alignment with the majority of the literature.

\section{Copper}

Copper is one of the most valuable metals for recycling as demand is high and it can be recycled and reused indefinitely, without losing any performance qualities [50]. Furthermore, recycling requires up to $85 \%$ less energy than primary copper production [59]. Copper used within transmission cables for wind farms is not generally recovered as transmission cables are left buried in situ-only the copper in the turbine itself is available for recovery [57-59]. Transmission cables are not covered within the scope of this assessment; however, so it is assumed that all copper waste within this study is available for recycling. LCAs performed by Vesats [33] and Chipindula et al. [49] assumed a $90 \%$ recycling rate, with a $10 \%$ loss to landfill, while an LCA performed by Martínez et al. [29] assumed a 95\% recycling rate. As a 90\% recycling rate has been assumed for steel or iron due to a large proportion being left in situ, it has been assumed that a $90 \%$ recycling rate for copper would be too low considering all copper waste covered within this study is available. A 95\% recycling rate has, therefore, been assumed here, in alignment with Martínez et al. [29]. 


\section{Aluminium}

Much like copper, aluminium is also endlessly recyclable. Also, aluminium recycling has a greater energy saving than copper, with recycled aluminium requiring $95 \%$ less energy than primary production (Aluminium Institute, 2018). Within the LCAs assessed, however, assumed aluminium recycling rates vary considerably. Chipindula et al. [49] assumed a recycling rate of $55.1 \%$, while Vestas [35] assumed a recycling rate of $90 \%$. A report by the Aluminium Federation (ALFED) [61], specifically in relation to the UK aluminium industry, described the following recycling rates:

- 92\%-98\% within the building and construction industry;

- $95 \%$ from transport applications; and

- $42 \%$ from packaging.

Based on these figures, a recycling rate of $95 \%$ has been assumed for aluminium waste from wind turbines in the UK. The recycling rates reported by Alfed [61] were assumed to be more accurate than those assumed by Chipindula et al. [49] and Vestas [35] as they are UK-specific. Correspondingly, packaging recycling figures were not considered relevant as the collection and waste management processes following wind turbine decommissioning were assumed to be more closely aligned to those within the transport and building and construction industries. $95 \%$ is the average of the range provided for the building and construction industry, which also aligns with the recycling rate for transport applications.

\section{Plastic}

Unlike copper and aluminium, plastic is not infinitely recyclable. Generally, plastic is only recyclable once or twice, eventually ending up incorporated within a non-recyclable commodity such as fabric [59-61]. Recyclability of plastic is also dependant on the type of plastic, of which there are many. Nevertheless, the recycling of plastics presents advantages such as reduction of environmental problems saving on both energy resources and materials [59, 60]. Each type of plastic has its own recycling rate and specific properties which dictate the end of life possibilities. Plastic recycling is complicated further by possible cross-contamination of plastics. For example, PET and PVC share many properties and often look very similar, so sorting techniques can be complicated. Without effective sorting, PVC contamination in a PET melt can contaminate the entire batch, reducing the quality of the product [60-63]. The plastic within wind turbines is used within electronics such as cables and the blades $[43,27,33]$. The types and quantities of each plastic are unclear, however, as this will vary depending on the turbine design. Different LCAs analysed reported various different types of plastic, including PE, PET, and PVC [27, 33, 47]. The availability of the plastics for recycling is also unclear as this is dependent on use, which, again, is dependent on specific turbine design. As plastic type and availability for recycling is unclear from the information available, it was not possible to make reliable assumptions regarding the end of life treatment of miscellaneous plastics in wind turbines. Also, assumptions within the literature vary, with LCAs performed by Vestas [35] and Martínez et al. [29] assuming $100 \%$ landfill, while LCAs performed by Chipindula et al. [49] and Haapala and Prempreeda [21] assumed 100\% incineration. An assumption regarding the management of plastic waste has, therefore, not been made due to a lack of relevant information. Plastic waste will, therefore, be excluded from the scenario-based assessment. It is unlikely, however, that this will have a significant impact upon the outcomes of the assessment as plastic accounts for less than $0.1 \%$ of overall turbine waste.

\section{Baseline assumptions}

A summary of the baseline assumptions regarding the waste management processes for each material is displayed in Table 4.

\section{Potential end of life improvements}

This section discusses improvements that could be made to the assumed current practice waste management processes. Improvements discussed within this section are defined as such based on movement up the waste hierarchy. Prevention is the most favourable option according to the waste hierarchy, followed by re-use, recycling, another recovery (such as heat recovery), and finally disposal according to DEFRA [41]. As this study focuses on the waste from turbines that have already been commissioned, prevention is not discussed here as it does note apply to the materials being assessed. It should be mentioned, however, that to maximise the sustainability of wind turbines, prevention should be considered throughout the design of future projects.

\section{Waste materials reuse}

When a wind turbine approaches the end of its operational lifetime, there are three options for operators to consider: Decommissioning, part repowering (life extension), or full repowering [61]. Decommissioning generally results in the waste management processes outlined in Table 4, but opportunities for life extension or reuse of parts provide possible, more sustainable, alternatives. Part repowering involves the replacement of certain components during the operational lifetime of a turbine to increase its lifespan, which can reduce overall waste as key aspects such as foundations and towers are reused according to 
the North American Wind Power report [66]. Full repowering involves full decommissioning of a wind turbine and commissioning of, generally, a larger model [64-67]. Full repowering is, therefore, not included here as waste is not necessarily reused. Any that is reused will fall into the reuse and remanufacture category discussed below.

\section{Reuse and remanufacture}

If turbines are still in relatively good condition at the end of their operational lifetime, the turbine structures (excluding foundations) can sometimes be reused entirely or broken down into their constituent parts. These parts can then be remanufactured and reused either within the wind power industry or elsewhere [64-67]. Foundations are not reusable in these instances and are disposed of as per the current practice described in Table 4. The secondhand wind turbine market in the UK generally involves private or community projects. For example, in 2004, the community on the Isle of Gigha in Scotland bought three used Vestas V27 turbines, while private companies such as GlaxoSmithKline and Nissan have also been known to purchase second-hand turbines to power their plants and factories [64-67]. The reuse of turbines in this way makes economic sense for small projects such as these as wind turbines have been shown to reduce in value to $<10 \%$ of their initial value after 15 years [64-67]. The size of the second-hand market in the UK is unclear. However, turbines can also be sold overseas to developing markets such as those in Eastern Europe and Latin America [27, 28]. Second-hand turbines are unlikely to have an operational lifetime of 20 years as before, so 10 years will be assumed for the scenario-based assessment. Every two second-hand turbines sold within the UK will, therefore, be assumed to, on average, reduce demand for one new turbine as each has half the operational lifetime of a new turbine. Each second-hand turbine is, therefore, assumed to reduce overall wind turbine waste by $50 \%$ of an average turbine's materials (excluding foundations as new foundations are required). Second-hand turbines sold overseas, however, will represent a waste reduction of $100 \%$ of an average turbine's materials (excluding foundations) as, regardless of the operational lifetime, the waste will not be generated within the UK.

Remanufacture and reuse is another second-hand market that could be further explored. Following decommissioning and dismantling of a turbine, many components can be remanufactured to as new condition and reused [64]. Although reuse within the industry provides an opportunity to reuse almost all components (excluding foundations), it is limited by advancements in wind turbine technology as old parts such as blades may not be applicable within modern turbine designs. Also, blades cannot be remanufactured due to the nature and structure of composite materials, so only those in good enough condition are reusable [64-70]. Blades will, therefore, not be included within the remanufacturing and reuse scenario as a worst-case scenario.

There is also a potential scope for the remanufacture and reuse of turbine components outside the wind power industry. For example, components such as gearboxes could be applicable within other industries such as for offroad machinery and aerospace or military operations [64]. For the scenario-based assessment, it has been assumed that all components except the foundations, tower, and blades are reusable within other industries. The foundations are assumed to be left in situ, while the blades and towers are designed specifically for their purpose so are assumed to not be useful within other industries.

\section{Part repowering}

Part repowering involves the replacement of certain components within a turbine with new equipment and technology to improve power output or extend the operational lifetime. Part repowering can involve the replacement of any component except the tower or foundation, either through individual part replacement or complete replacement of the nacelle, blades, and hub together [62-65]. Part repowering differs from the type of part replacement factored into the waste calculations above, because it involves the incorporation of improved technology, rather than replacement of worn out parts.

Extending the operational lifetime of a turbine in this way essentially reuses the foundations and tower. An operational lifetime extension of 10 years, for example, accounts for $50 \%$ of an average operational lifetime, so the equivalent of 50\% of an average turbine's tower and foundation material waste will be reused. Although part repowering involves the addition of new components, it is assumed for the scenario-based assessment that the additional materials required for a 10-year lifetime extension do not exceed $50 \%$ of the materials required within a whole turbine (excluding tower and foundations). Therefore, the additional materials are accounted for by the proportional extension to the operational lifetime.

Due to the many variables involved regarding the repowering of turbines or re-use of turbines or specific components, it is not possible to calculate realistic projections for such practices within the scope of this study. Therefore, the assessments have calculated potential waste savings based on various scenarios merely to demonstrate the positive impacts such practices could achieve. It is unknown whether such scenarios are realistic, but they provide milestones for which the industry can aim. 


\section{Recycling and heat recovery}

As per the current practice waste management assumptions outlined in Table 4, copper, aluminium, and steel or iron are already recycled where possible, so are not discussed within this section. The focus of this section will be on composite materials, concrete, and the currently unavailable steel or iron within turbine foundations. These are the only materials with current practice waste management practices lower down the waste hierarchy than recycling and heat recovery.

\section{Composite materials}

As composite materials are currently landfilled in the UK, any other option within the waste hierarchy is an improvement. Composite materials can be reused in some circumstances. Alternative options for when reuse is not feasible are considered within the following section. Recycling is the most favourable alternative after reuse [73]. One method of recycling FRP materials is to simply break them down into smaller fragments, which can then be used within various construction materials such as aggregates [52]. Recycling FRP materials in this way reduce the need for the virgin construction materials being replaced, thereby reducing embodied carbon emissions. An idea developed by Bank et al. [69] involved the exploration of conceptual designs for architectural applications for used turbine blades. Moreover, Bank et al. [69] identified the demand for quality building materials within informal settlements in developing countries as an opportunity to recycle turbine blade waste. Flooding was identified as a key issue in such settlements. Bank et al. [69] proposed cutting cross sections of the blade roots (the widest part of the blades) for use as elevation platforms for houses to address this issue. Developing the housing concept further, it was suggested that large, curved blade segments could be used as sloping roofs, which would be ideal as turbine blades are designed to cope with harsh weather conditions. A further example of composite materials being utilised within architecture is the incorporation of turbine blades within the design of a bridge in Nørresundby, Denmark [66]

Table 4 Baseline assumptions for current waste management procedures in the UK

\begin{tabular}{ll}
\hline Material type & Waste management procedure \\
\hline Steel or iron & $87 \%$ recycled, 13\% landfilled \\
Concrete & $100 \%$ landfilled \\
Composite materials & $100 \%$ landfilled \\
Copper & $95 \%$ recycled, 5\% landfilled \\
Aluminium & $95 \%$ recycled, 5\% landfilled \\
Plastic & N/A \\
\hline
\end{tabular}

Wind turbine blades can also be recycled for use as bus shelter roofs, public seating, playground items, art installations, or artificial reefs [52, 66, 67]. Furniture items and skateboards provide further recycling options [66, 67]. For composite materials not recycled, energy recovery through incineration provides another option. Energy recovery involves incinerating the calorific content of composite materials and harnessing the heat produced to generate electricity [67]. This method, however, can be hindered by the glass fibre content of the blades, which can account for up to $70 \%$ of the material $[67,68]$. Besides, the incineration process must be effectively controlled to avoid harmful emissions and the residues and ash from the process must be landfilled [52]. One final method for managing waste composite material, which combines incineration and recycling, involves the incineration of turbine blade waste in cement kilns to produce the energy required for cement production while also providing some key cement ingredients. Cement production relies on significant quantities of sand, which is also the main constituent of the glass fibres present in GRP $[68,69]$. During incineration, the polymer connecting the glass fibres is burnt away, providing the heat for cement production, while the glass and fillers remain to become part of the cement $[68,69]$. This method not only reduces the raw materials required for cement production, but the energy required too. In addition, because the majority of residues are used for cement production, minimal waste is landfilled [52]. The Neocomp facility in Germany recycles fibreglasscontaining substances in this way, including wind turbine blades, and has a capacity of 80,000 tonnes of FRP waste per year $[73,75]$. The scenario-based assessment below considers the benefits that could be realised by having such a facility in the UK. The various other recycling options discussed within this section have also been considered.

\section{Foundations}

Matos [74], developed scenarios for onshore foundation recycling, in which the foundations are demolished and the materials recovered. Matos [74] assumed a 70\% and 80\% recovery rate for steel and concrete, respectively. This process and recovery rate have been assumed within the scenario-based assessment for onshore foundations. Recovered concrete can be recycled for use in building materials, road construction, and land reclamation projects to reduce the need for virgin materials and, therefore, reduce associated $\mathrm{CO}_{2}$ emissions (The Concrete Centre, 2018). There is no indication within the literature as to whether offshore foundation piles can be fully removed to increase the quantity of steel or iron available for recycling. As offshore technology is still in its infancy, the technology required to perform the current practice process of cutting piles a few meters 
below the seabed is not yet readily available [25]. It has, therefore, been assumed for the scenario-based assessment that improvements to the current practice for offshore turbine foundations are not yet feasible.

\section{Scenario-based assessment}

The scenarios developed within this section have been informed by the potential end of life waste management improvements discussed above. The assumptions made are followed by quantification of the possible waste and carbon savings. As stated above in relation to turbine reuse options, realistic projections of future waste management procedures are not possible within the scope of this assessment. Scenarios have, therefore, been developed merely to demonstrate the potential positive impacts the various waste management improvements could have. The scenarios have been developed in accordance with what seems realistic based on the tone of the literature.

\section{Reuse scenarios}

The following three reuse scenarios have been developed based on possible waste management improvements as follows:

- Scenario 1: The use of second-hand wind turbines, both within the UK and overseas;

- Scenario 2: The remanufacture and reuse of wind turbine components, both within the wind power industry and elsewhere; and

- Scenario 3: Life extension of wind turbines through part repowering.

The specific assumptions made for each of these scenarios are discussed in more detail below, followed by the potential waste and carbon savings calculated. Carbon savings were calculated based on waste reduction figures as reuse of turbines or components will reduce the demand for new turbines or components, and, therefore, mitigate the associated embodied carbon emissions. Embodied carbon values were taken from the ICE Database [48]. Part replacement waste has not been included within the calculations for Scenarios 1, 2, and 3 as it is assumed that waste from part replacement, i.e., worn out or broken parts, is not reusable.

\section{Scenario 1: Second-hand wind turbines}

Assumptions:

- All components of a second-hand wind turbine are reused for 10 years beyond their original operational lifetime of 20 years.
- $10 \%$ of overall turbine waste, excluding that within foundations, is assumed to be reused in this way- $5 \%$ within the UK and 5\% overseas.

- Turbine waste reused in this way within the UK reduces the associated waste produced by $50 \%$ as the 10 -year assumed lifetime is $50 \%$ of the operational lifetime of a new turbine.

- Turbine waste reused in this way overseas reduces the associated waste produced by $100 \%$ as the waste will not be produced in the UK.

To exclude the foundation waste, concrete was excluded from the calculations. Also, $13 \%$ of steel or iron waste was excluded as this is the average proportion of overall steel or iron waste incorporated within foundations, as calculated in the section above. Waste reduction quantities and associated GHG emissions savings are displayed in Fig. 17.

The stacked bars in Fig. 17 represent the waste savings (kt) within each period, while the stacked areas represent the GHG emissions savings $\left(\mathrm{tCO}_{2} \mathrm{e}\right)$.

\section{Scenario 2: Remanufacture and reuse}

Assumptions:

- $10 \%$ of applicable turbine waste is assumed to be reused in this way-5\% within the wind power industry and 5\% elsewhere.

- For reuse within the wind power industry:

- All waste except that within blades and foundations is applicable.

- A waste reduction of $100 \%$ is achieved by applicable materials reused in this way as these components are remanufactured to as new condition and reduce the need for new parts.

- For reuse within other industries:

- All waste except that within blades, towers, and foundations are applicable.

- A waste reduction of $100 \%$ is achieved by applicable materials reused in this way as the waste will not be produced within the wind power industry.

Foundation waste was excluded from the calculations, as described above for Scenario 1. The average proportion of steel or iron waste within towers was calculated for steel or iron waste within foundations. This was then also excluded from calculations that were not applicable for reuse. The average quantity of aluminium and steel or iron within turbine blades was also excluded from the calculations. Quantities of aluminium and steel or iron 
were extrapolated from known composite material waste quantities using blade composition proportions provided by Andersen [27] and Andersen et al. [28] (displayed in Table 3). Waste reduction quantities and associated GHG emissions savings are displayed in Fig. 18.

The stacked bars represent the waste savings (kt) within each period, while the stacked areas represent the GHG emissions savings $\left(\mathrm{tCO}_{2} \mathrm{e}\right)$.

\section{Scenario 3: Life extension}

\section{Assumptions:}

- $10 \%$ of turbines in the UK are repowered in this way, with an average life extension of 10 years.

- Towers and foundations are the only components reused in this way.

- Waste associated with towers and foundations reused in this way is reduced by $50 \%$ as the 10 -year assumed lifetime is $50 \%$ of the operational lifetime of a new turbine.

- $5 \%$ of tower and foundation waste is, therefore, saved (50\% of $10 \%)$.

Specific waste quantities associated with foundations and towers were calculated as described above for Scenario 1 and Scenario 2. Waste reduction quantities and associated GHG emissions savings for Scenario 3 are displayed in Fig. 19.

As illustrated in Figs. 17 and 18, the stacked bars represent the waste savings (kt) within each time period, while the stacked areas represent the GHG emissions savings $\left(\mathrm{tCO}_{2} \mathrm{e}\right)$. Figures 17,18 , and 19 demonstrate the significant waste and carbon savings that are possible through the reuse of whole turbines or specific components. Steel or iron is reused within all three scenarios and accounts for most of the waste and carbon savings within Scenarios 1 and 2. Due to the reuse of foundations in Scenario 3, however, and the significant quantity of concrete associated with foundations, concrete accounts for most of the waste saved in this case. This is not reflected within the GHG emissions savings figures for Scenario 3, however. This is because steel has a significantly higher embodied carbon value [48], so less steel needs to be reused in comparison to concrete to save the same amount of GHG emissions. This trend is also demonstrated within Scenarios 1 and 2 for aluminium, copper and composite materials. Aluminium has the highest embodied carbon value, which is demonstrated by the significant change in the proportional contribution of aluminium to waste savings in comparison to GHG emissions savings. On average, aluminium accounted for $0.7 \%$ of the waste savings in Scenario 1 but accounted for $3.7 \%$ of the GHG emissions savings.

\section{Recycling and heat recovery scenarios}

The following three reuse scenarios have been developed in relation to three of the waste management improvement possibilities:

- Scenario 4: The recycling of composite materials into aggregate;

- Scenario 5: The demolition and subsequent recycling of onshore foundations; and

- Scenario 6: The combined recycling and heat recovery from composite materials.

The specific parameters of these scenarios are discussed in more detail below. Potential waste and carbon savings are also presented below each scenario. Part replacement figures are included within the calculations for Scenarios 4 and 6 as even worn out or broken blades are assumed to be available for recycling.
Fig. 17 Waste reduction quantities and GHG emissions savings expected within each period according to Scenario 1

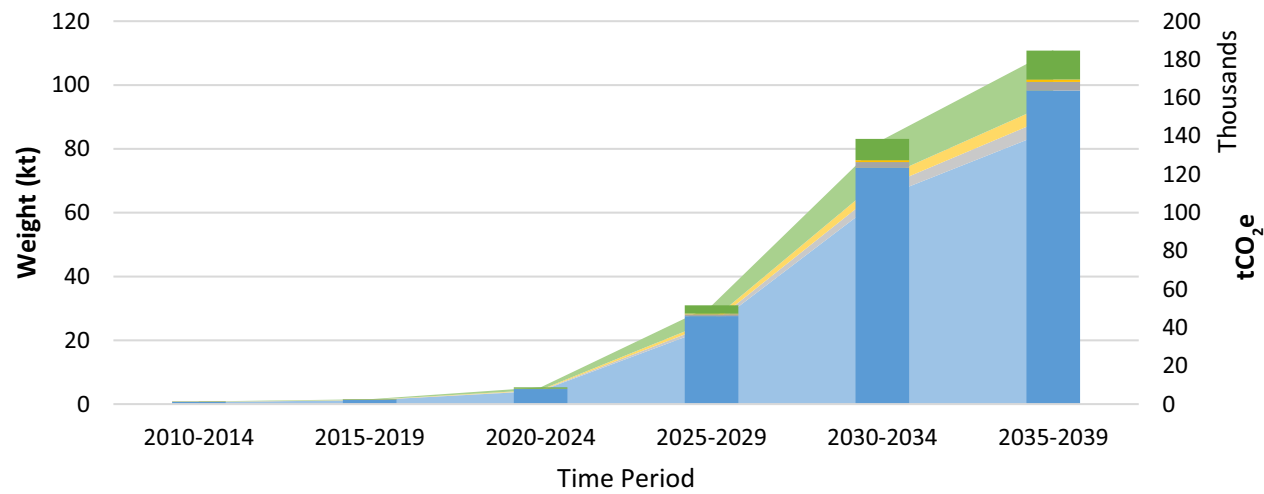

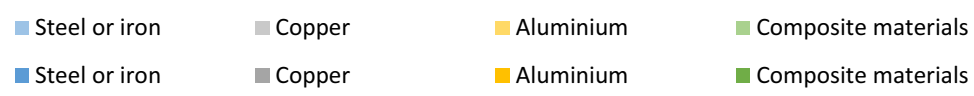


Fig. 18 Waste reduction quantities and GHG emissions savings expected within each period according to Scenario 2

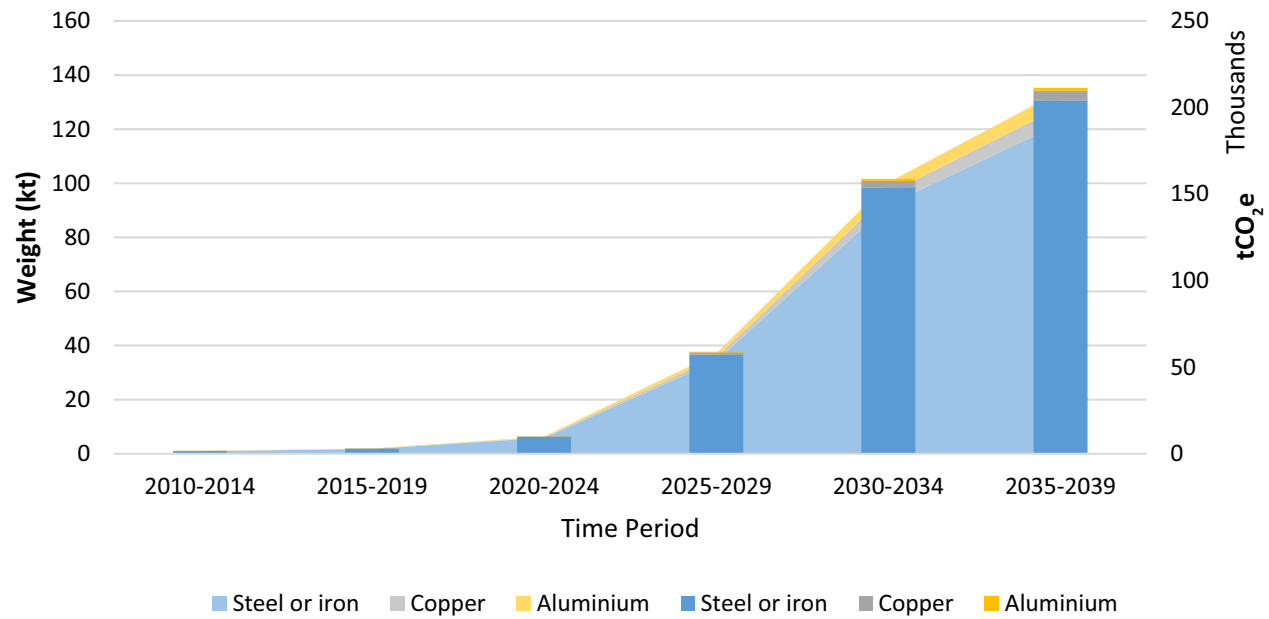

The recovery rates of $70 \%$ and $80 \%$ for steel or iron and concrete, respectively, were adapted from the study by Matos [74]. There is also concrete within the gravity-based foundations installed in the Blyth Offshore Wind Demonstration Project (Phase 1). However, these foundations have been excluded from these calculations due to the uncertainty surrounding the eventual waste management procedure. Recycled steel or iron resulting from this scenario will have a lower embodied carbon factor than an average piece of steel or iron but will still have some embodied carbon due to the energy required for recycling. The difference between the embodied carbon for 'recycled steel' and 'general steel' [48] has, therefore, been calculated and used for the GHG emissions savings calculations here. Recycled concrete is assumed to be recycled into aggregate. Therefore, the embodied carbon factor for aggregate is applied here [46-48].

The stacked bars in Fig. 21 represent the quantity of each material recovered for recycling, while the stacked area aspect represents the associated GHG emissions savings. Much like the pattern observed in Fig. 19, concrete accounts for most of the waste recovery here, while steel accounts for most of the carbon emissions savings. Again, this is due to variations in embodied carbon factors. The significant difference between the aggregate embodied carbon factor $(0.0052$ $\left.\mathrm{kgCO}_{2} \mathrm{e} / \mathrm{kg}\right)$ and that used for steel or iron $\left(0.99 \mathrm{kgCO}_{2} \mathrm{e} / \mathrm{kg}\right)$ explains this dramatic shift.

\section{Scenario 6: Recycling and heat recovery}

Assumptions:

- $50 \%$ of overall composite material waste is treated this way.

- $35 \%$ of the composite material treated in this way is incinerated for heat recovery. 
Fig. 19 Waste reduction quantities and GHG emissions savings expected within each time period according to Scenario 3

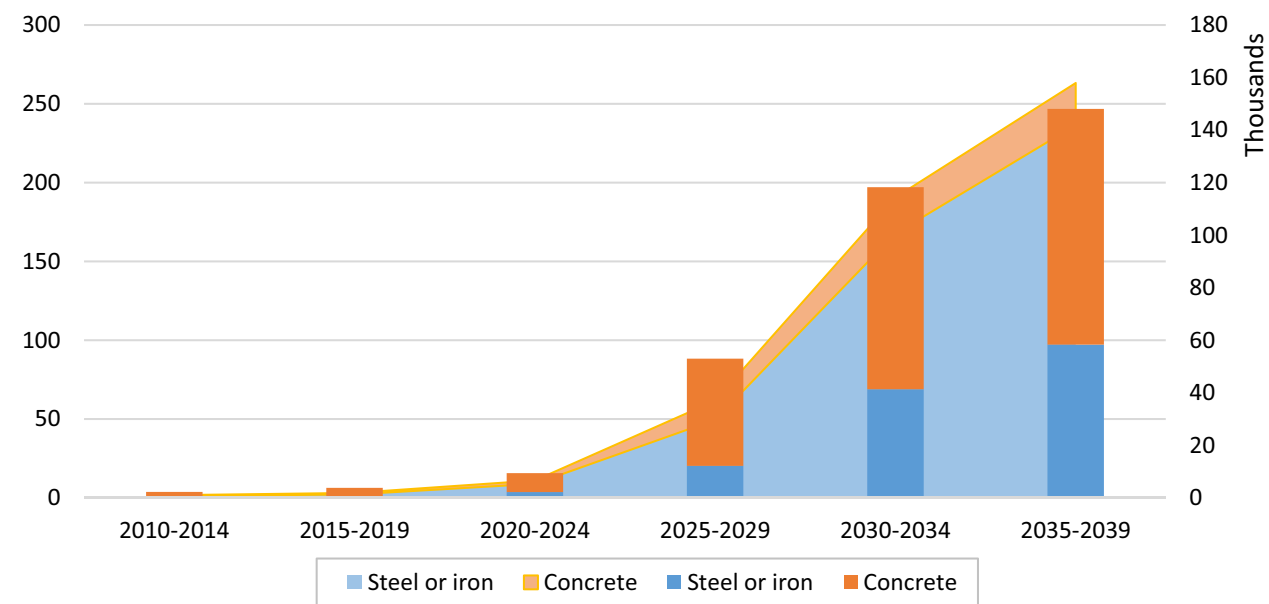

- The remaining $65 \%$ is recycled into a constituent of cement.

A report by Wind Europe [70] states that the material composition turbine blades is generally $30 \%-40 \%$ resin and $60 \%-70 \%$ reinforcing fibres. The resin is incinerated during this process and the reinforcing fibres become part of the cement. Averages of $35 \%$ and $65 \%$ have, therefore, been calculated and assumed for heat recovery and recycling, respectively. Carbon savings have not been calculated for this scenario as is it not feasible to perform such calculations within the scope of this assessment [70-72]. Although Fiberline [72] has reported the reduction in raw materials required by this method in comparison to conventional cement production, the ICE Database does not contain embodied carbon factors for them all. Also, the complexity of GHG emission calculations is increased by the additional variable of combustion. All specific constituents and their associated embodied carbon and combustion factors would need to be researched. This aspect has, therefore, been excluded from this scenario.

Overall waste assumed available within Scenario 6 is represented by the green bars in Fig. 22. This is then broken down into the assumed quantity available for heat recovery and recycling. Although the 50\% recovery rate for treatment via this method may seem ambitious, the Neocomp facility in Germany, described has a treatment capacity of 80,000 tonnes per year [71]. That equates to a capacity of 400,000 tonnes over a 5-year period, which exceeds even the overall composite waste expected within the 2035-2039 period (around 260,000 tonnes). Therefore, if a comparable facility was installed within the UK, it would not be unreasonable to assume all composite waste from turbines could be treated in this way.

There are many different wind turbine designs installed within the UK, both onshore and offshore. On average, onshore wind turbines are smaller than those installed offshore due to fewer size restrictions offshore. Although fewer size restrictions enable offshore turbines to generate more power, offshore locations present challenges not faced by onshore turbines, primarily regarding foundation design. Over time, various designs have been developed to overcome challenges posed by various seabed conditions and sea depths to optimise wind potential. Despite the significant design variations within the wind power industry, this study has attempted to accurately calculate the waste expected as a result of wind turbine decommissioning in the UK. This section discusses the implications of the results obtained and suggests ways in which these results could be used, primarily in relation to targeted, effective investment in improved waste management practices.

As expected, the rapidly rising turbine installation rates over the last few decades are reflected within the results of this study by an equally rapid rise in waste associated with decommissioning. Currently, overall waste generation is around $37 \mathrm{kt}$ annually. However, this figure is set to rise to over $1200 \mathrm{kt}$ annually by 2035-2039. Without improvements to current waste management practices and strategic investment, significant portions of this waste will end up in landfill in the UK.

The priority materials in terms of waste management improvements should be concrete and composite materials as these are currently landfilled in the UK generally, which is the least favourable disposal method according to the waste hierarchy [40]. This study has identified several ways in which these materials could be treated in more favourable ways, such as reuse, recycling, and heat recovery options for composite materials, and a recycling option for concrete.

Although concrete and composite materials should be prioritised to avoid landfilling, this should not be the only focus within the waste management industry. Recycling still uses energy, albeit less than virgin material production, and as such heavily recycled materials such as aluminium, copper, steel, and iron can be treated more sustainably. This 
Fig. 20 Composite material recycling rate and resultant GHG emissions savings expected within each period according to Scenario 4
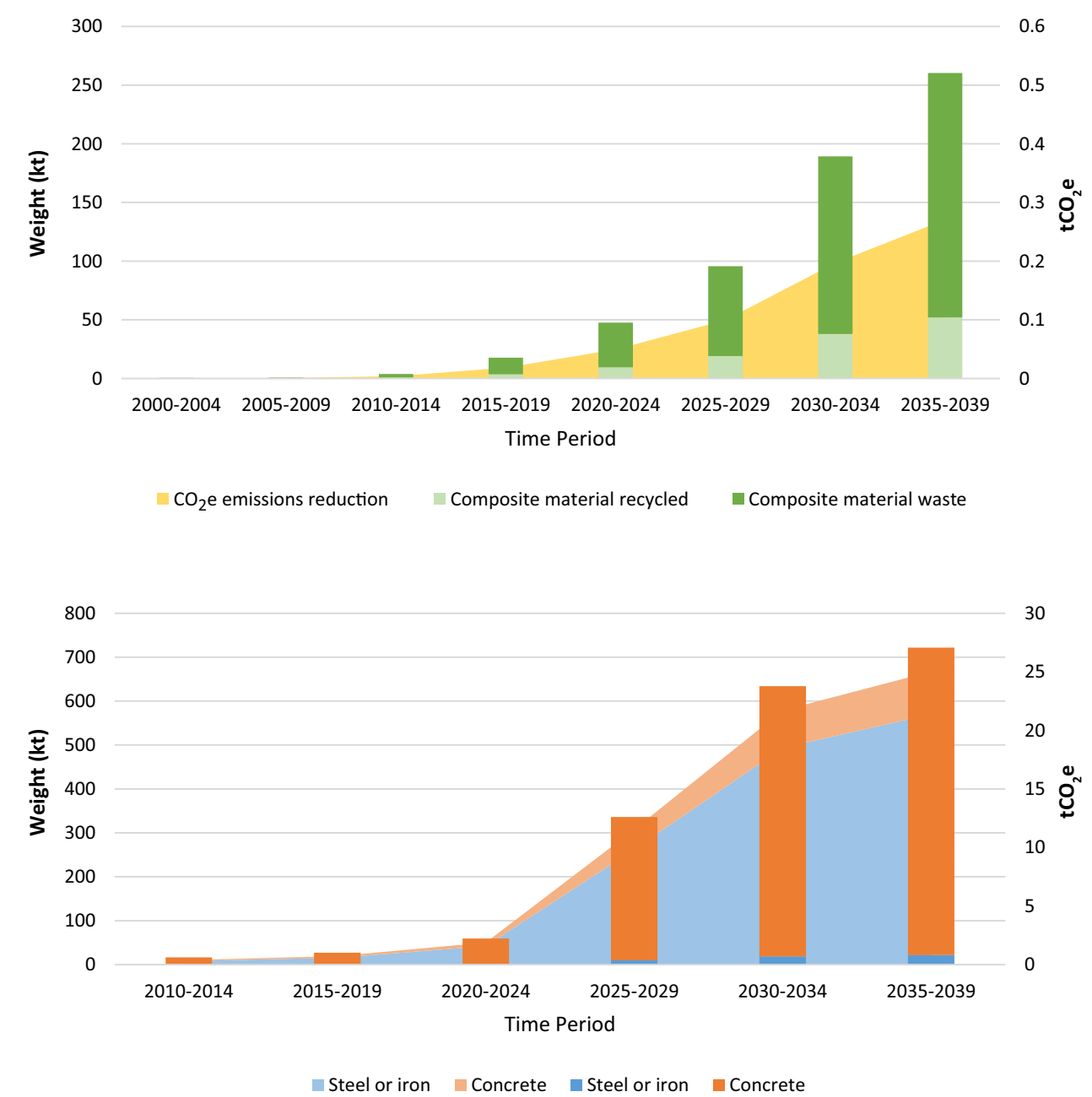

$\stackrel{0}{U}^{\sim}$
Fig. 21 Concrete and steel or iron recycling rates and resultant GHG emissions savings expected within each period according to Scenario 5 study has explored various reuse options such as the use of second-hand turbines within the UK and overseas, the remanufacture and reuse of components within the wind power industry and elsewhere, and the reuse of towers and foundations through the repowering of existing turbines.

The scenario-based assessments conducted within this report have attempted to demonstrate the significant benefits that could be achieved by various reuse, remanufacturing, recycling, and heat recovery options. An attempt has been made to accurately quantify these benefits, both in terms of the waste hierarchy and GHG emissions savings. These scenarios should be used in combination with the overall waste calculations to inform policy development and waste management investment decisions. For example, increasing the landfill tax for composite materials would encourage the exploration of alternative disposal methods. Similarly, investment in infrastructure like the Neocomp facility in Germany could lead to the more sustainable treatment of all composite waste from the wind power industry for the foreseeable future [75]. The overall waste figures presented could be used as a guideline in terms of capacity requirements over time.

In relation to policy development and investment decisions, future trends expected within the wind power industry should also be considered. For example, with the continued move away from onshore turbines, toward offshore technology, material proportions within waste streams will vary over time. Unless gravity-based foundations become commonplace, concrete waste is likely to decrease over time as other offshore turbine designs will predominantly use steel. Also, the end of life management of offshore foundation piles should be explored and, where possible, alternatives to landfilling of significant portions of these foundations should be developed.

Furthermore, future trends will affect the outcomes and relevance of some of the scenario-based assessments. For example, the installation of larger turbines such as the 12 MW GE Haliade X prototype Vox [76] could limit the applicability of the second-hand turbine scenario. Such large turbines may be challenging in terms of intact 
Fig. 22 Quantity of overall composite material available for treatment within each period according to Scenario 6, also split between recovery and recycling

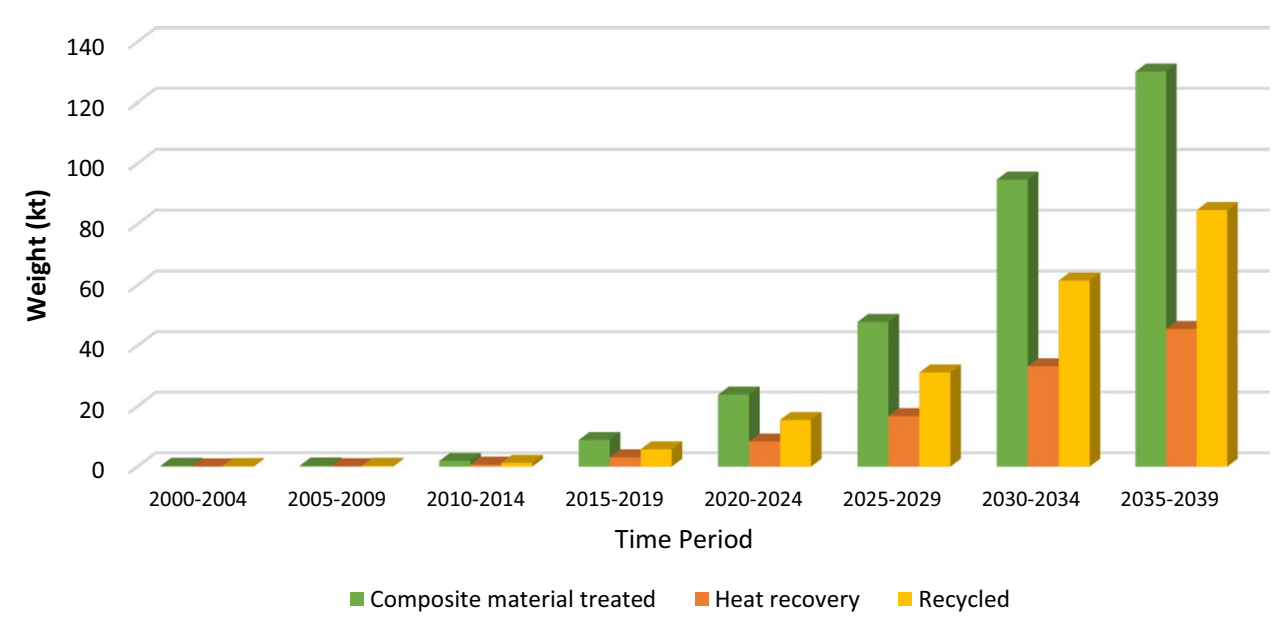

decommissioning, transportation, and finding viable locations for subsequent reinstallation.

Turbine design options at the beginning of the lifecycle and environmental impacts throughout the operational lifetime should also be considered to maximise sustainability in areas such as GHG emissions. A whole lifecycle view was not feasible within the scope of this assessment, but designing turbines to ensure waste is reusable following decommissioning, or easily accessible to recycling waste streams, would further maximise sustainability benefits. Material use avoidance options should also be considered throughout the design of turbines as this is the most favourable option within the waste hierarchy [40]. Incorporation of low-carbon technologies and materials such as Cemfree (a cement-free concrete that has up to $88 \%$ less embodied carbon compared with other cement types; DB Group, 2018), also provides opportunities for sustainability improvements [77].

Finally, wind turbines are not the only source of waste following wind farm decommissioning. Balance-of-plant infrastructure such as substations and power cables also have significant material requirements. These aspects of a wind farm should also be considered within further research.

\section{Conclusions}

This study has quantified expected waste production as a result of wind turbine decommissioning in the UK to inform policy development and investment decisions regarding waste management procedures. The results of this study should be used to help improve upon the current practice waste management processes within the UK to maximise the sustainability of the wind power industry, which is regarded as a sustainable alternative to energy production from fossil fuels. Examples of improved waste management procedures have been discussed, such as reuse, remanufacture, recycling, and heat recovery through incineration. The scenarios developed based on these waste management improvements have quantified potential environmental benefits, such as reduced waste to landfill and reduced GHG emissions. To maximise the sustainability of the wind power industry, further research should explore future trends in terms of turbine design and assess the impacts these trends will have on the conclusions drawn within this report. Moreover, a wholelifecycle approach should be taken within the industry to truly maximise sustainability. Carefully considered changes made in the design phase of a turbine's lifecycle could positively impact upon the availability of materials to the improved waste management practices at the end of life phase.

Open Access This article is licensed under a Creative Commons Attribution 4.0 International License, which permits use, sharing, adaptation, distribution and reproduction in any medium or format, as long as you give appropriate credit to the original author(s) and the source, provide a link to the Creative Commons licence, and indicate if changes were made. The images or other third party material in this article are included in the article's Creative Commons licence, unless indicated otherwise in a credit line to the material. If material is not included in the article's Creative Commons licence and your intended use is not permitted by statutory regulation or exceeds the permitted use, you will need to obtain permission directly from the copyright holder. To view a copy of this licence, visit http://creativecommons.org/licenses/by/4.0/.

\section{References}

1. Carle, J. 2015. Climate change seen as top global threat. Pew Research Centre, Washington, DC, USA, p. 1-17

2. IPCC. 2007. Climate Change 2007: impacts, adaptation and vulnerability: contribution of Working Group II to the fourth assessment report of the Intergovernmental Panel. Geneva: IPCC. Available from: https://www.ipcc.ch/pdf/assessment-report/ar4/wg2/ ar4_wg2_full_report.pdf. [Accessed 15 February 2018]. 
3. Blanco, G., Gerlagh, R., Suh, S., et al. 2014. Drivers, Trends and Mitigation. Climate Change 2014: Mitigation of Climate Change. Contribution of Working Group III to the Fifth Assessment Report of the Intergovernmental Panel on Climate Change [online]. pp. 351-412. [Accessed 18 February 2018].

4. DBEIS. 2017. UK Energy in Brief 2017 [online]. London: DBEIS. Available from: https://www.gov.uk/government/uploads/system/ uploads/attachment_data/file/631146/UK_Energy_in_Brief_2017. pdf. [Accessed 16 February 2018].

5. UN. 1998. Kyoto Protocol To the United Nations Convention on Climate Change [online]. New York: UN. Available from: https://unfccc.int/ resource/docs/convkp/kpeng.pdf. [Accessed 14 February 2018].

6. UNFCCC. 2015. Paris Agreement [online]. Bonn: UNFCC. Available from: https://unfccc.int/files/essential_background/conve ntion/application/pdf/english_paris_agreement.pdf. [Accessed 14 February 2018].

7. Climate Change Act 2008 [online]. 2008. Chapter 27. (2008) Legislation Gov. Available from: https://www.legislation.gov. uk/ukpga/2008/27/pdfs/ukpga_20080027_en.pdf. [Accessed 03 February 2018].

8. DECC. 2011. The Carbon Plan: Delivering our low carbon future [online]. London: DECC. Available from: https://www.gov.uk/ government/uploads/system/uploads/attachment_data/file/47613 13702-the-carbon-plan-delivering-our-low-carbon-future.pdf. [Accessed 13 February 2018].

9. Carbon Brief. 2018. Analysis: Low-carbon sources generated more UK electricity than fossil fuels in 2017. Available from: https ://www.carbonbrief.org/uk-low-carbon-generated-more-than-fossi 1-fuels-in-2017. [Accessed 14 February 2018].

10. Gasch, R., and Twele, J. 2012. Wind Power Plants: Fundamentals, Design, Construction and Operation [online]. 2nd ed. Berlin: Springer-Verlag Berlin Heidelberg. [Accessed 17 February 2018].

11. Kaldellis, J. K., and Zafirakis, D. 2011. The wind energy (r)evolution: A short review of a long history. Renewable Energy [online]. 36 (7), pp. 1887-1901. [Accessed 16 February 2018].

12. Vestergaard, J., Brandstrup, L., and Goddard, R. D. 2004. A Brief History of the Wind Turbine Industries in Denmark and the United States. Academy of International Business [online]. pp. 322-327. [Accessed 16 February 2018].

13. REF. 2009. UK Renewable Energy Industry [online]. London: REF. Available from: https://warwick.ac.uk/fac/soc/ier/ngrf/stem/ basics/sources/stem-_renewable_energy_industry_final_versi on-v3.pdf. [Accessed 16 February 2018].

14. Berkely Lab. 2016. Reducing Wind Energy Costs through Increased Turbine Size: Is the Sky the Limit? [online]. Berkeley: Berkeley Lab. Available from: https://emp.lbl.gov/sites/all/files/ scaling_turbines.pdf. [Accessed 15 February 2018].

15. RAENG. 2014. Wind Energy [online]. London: RAENG. Available from: https://www.raeng.org.uk/publications/reports/windenergy-implications-of-large-scale-deployment. [Accessed 03 February 2018].

16. Troen, I., and Petersen, E. L. 1989. European Wind Atlas [online]. Roskilde: Ris $\varnothing$ National Laboratory. [Accessed 12 February 2018].

17. Eerens, H., and De Visser, E. 2008. Wind-energy potential in Europe 2020-2030 [online]. Available from: https://www.resea rchgate.net/publication/239591485_Wind-energy_potential_in_ Europe_2020-2030. [Accessed 16 February 2018].

18. EWEA. 2013. Deep water - The next step for offshore wind energy [online]. Brussels: EWEA. Available from: https://www.ewea. org/fileadmin/files/library/publications/reports/Deep_Water.pdf. [Accessed 16 February 2018].

19. 4C Offshore. 2019. 4C Offshore - Offshore Wind Farms. 2017; Available at: https://www.4coffshore.com/windfarms/. [Accessed March 7, 2018].
20. Carbon Trust. 2015. Floating Offshore Wind: Market and Technology Review [online]. London: Carbon Trust. Available from: https ://www.carbontrust.com/media/670664/floating-offshore-windmarket-technology-review.pdf. [Accessed 16 February 2018].

21. Haapala, K. R., and Prempreeda, P. 2014. Comparative life cycle assessment of 2.0 MW wind turbines. Int. J. Sustainable Manufacturing [online]. 3 (2), pp. 170-185. [Accessed 17 February 2018].

22. RenewableUK. 2015. Wind Energy in the UK - State of the Industry Report [online]. London: RenewableUK. Available from: https ://c.ymcdn.com/sites/www.renewableuk.com/resource/resmgr/ publications/reports/soi_report_summary_2015.pdf. [Accessed 16 February 2018].

23. CEC. 2009. Wind Energy - The Facts [online]. Melbourne: CEC. Available from: https://cleanenergycouncil.org.au. [Accessed 19 February 2018].

24. Kim, J., Guillaume, B., Chung, J., et al. 2015. Critical and precious materials consumption and requirement in wind energy system in the EU 27. Applied Energy 139: 327-334.

25. UKWED. 2018. UKWED search, Basic search [online]. Available from: https://www.renewableuk.com/page/UKWEDSearc h. [Accessed 03 February 2018].

26. The Wind Power. 2018. Online access, Wind farms [online]. Available from: https://www.thewindpower.net/windfarms_list_ en.php. [Accessed 23 February 2018].

27. Andersen, N. 2015. Wind turbine end-of-life: Characterisation of waste material [online]. MSc, University of Gavle. Available from: https://www.diva-portal.org/smash/get/diva2:87336 8/FULLTEXT01.pdf. [Accessed 07 February 2018].

28. Andersen, P. D., Bonou, A., Beauson, J., et al. 2014. Recycling of wind turbines [online]. Denmark: DTU International Energy Report 2014. Available from: https://orbit.dtu.dk/files/10245 8629/DTU_INTL_ENERGY_REP_2014_WIND_91_97.pdf. [Accessed 18 February 2018].

29. Martínez, E., Sanz, F., Pellegrini, S., et al. 2009. Life-cycle assessment of a 2-MW rated power wind turbine: CML method. The International Journal of Life Cycle Assessment[online] 14(1): 52-63. Available online at: https://link.springer.com/ article/10.1007/s11367-008-0033-9. [Accessed 16 February 2018].

30. PERI. 2001. Wind Turbine - Materials and Manufacturing Fact Sheet [online]. Rockville: PERI. Available from: https://cites eerx.ist.psu.edu/viewdoc/download?doi=10.1.1.464.5842\&re $\mathrm{p}=$ rep $1 \&$ type $=$ pdf. [Accessed 12 February 2018].

31. Zimmermann, T., M. Rehberger, and S. Gößling-Reisemann. 2013. Material flows resulting from large scale deployment of wind energy in Germany. Resources 2 (3): 303-334.

32. Composites World. 2012. Wind turbine blades: Glass vs. carbon fiber. Available from: https://www.compositesworld.com/artic les/wind-turbine-blades-glass-vs-carbon-fiber. [Accessed 25 February 2018].

33. Aerospace Engineering Blog. 2013. Composite Materials and Renewables: Wind Energy. Available from: https://aeros paceengineeringblog.com/composite-materials-wind-energy/. [Accessed 25 February 2018].

34. BOEM. 2016. Offshore Wind Energy. Available from: https:// www.boem.gov/Offshore-Wind-Energy/. [Accessed 25 February 2018].

35. Vestas. 2006. Life cycle assessment of offshore and onshore sited wind power plants based on Vestas V90-3.0 MW turbines [online]. Aarhus: Vestas. Available from: https://www. vestas.com/ /media/vestas/about/sustainability/pdfs/lca_v90_ june_2006.ashx. [Accessed 20 February 2018].

36. Malhotra, S. 2011. Selection, Design and Construction of Offshore Wind Turbine Foundations, Wind Turbines [online]. London: InTech. [Accessed 19 February 2018]. 
37. Kaiser, M. J., and Snyder, B. F. 2012. Offshore Wind Energy Cost Modelling [online]. 1st ed. London: Springer-Verlag London. [Accessed 15 February 2018].

38. Society for Underwater Technology. 2014. Guidance Notes for the Planning and Execution of Geophysical and Geotechnical Ground Investigations for Offshore Renewable Energy Developments [online]. London: Society for Underwater Technology. Available from: https://slideplayer.com/slide/5290227/ [Accessed 22 September 2018].

39. Hensel, J., Ravi Sharma, M.S., Baxter, C.D., et al. 2012. Development of a technology type factor for jacket structures for offshore wind turbines in Rhode Island. Journal of Renewable and Sustainable Energy 4 (6): 063120.

40. Properzi, S. and Herk-hansen, H. 2001. Life Cycle Assessment of a 150 MW Offshore Wind Turbine Farm at Nysted/Roedsand [online]. Available from: https://tethys.pnnl.gov/sites/default/ files/publications/Middelgrund_LCA_2001.pdf [Accessed 18 February 2018].

41. DEFRA. 2011. Guidance on applying the Waste Hierarchy [online]. London: DEFRA. Available from: https://www.gov. uk/government/uploads/system/uploads/attachment_data/ file/69403/pb13530-waste-hierarchy-guidance.pdf [Accessed 22 February 2018].

42. Cao, Z., O'Sullivan, C., Tan, J., et al. 2019. Resourcing the Fairytale Country with wind power: a dynamic material flow analysis. Environmental Science \& Technology 53 (19): 11313-11322.

43. Wind Power Offshore. 2018. Offshore Decommissioning Could Cost $U K £ 3.6 \mathrm{bn}$. Available from: https://www.windpoweroffsho re.com/article/1487845/offshore-decommissioning-cost-uk-36bn. [Accessed 18 February 2018].

44. Liu, P. and Barlow, C. Y. 2017. Wind turbine blade waste in 2050. Waste Management [online]. 62, pp. 229-240. [Accessed 22 February 2018]

45. BAM Nuttall. 2018. Presentation on the Blyth Offshore Wind Demonstration Project (Phase 1). Available from: https://www. bamnuttall.co.uk/case-study/blyth-offshore-demonstrator/.

46. Topham, E., and McMillan, D. 2017. Sustainable decommissioning of an offshore wind farm. Renewable Energy 102: 470-480.

47. Kiełkiewicz, A., Marino, A., Vlachos, C., et al. 2015.The practicality and challenges of using xl monopiles for offshore wind turbine substructures. Available from: https://www.esru.strath.ac. uk/EandE/Web_sites/14-15/XL_Monopiles/cost.html\#introducti on, [Accessed: 28 February 2019].

48. Inventory of Carbon and Energy (ICE). 2011. ICE Database (v2.0) [online]. Available from: https://www.carbonsolutions .com/resources/ice\%20v2.0\%20-\%20jan\%202011.xls [Accessed 18 November 2018]

49. Chipindula, J., Botlaguduru, V.S.V., Du, H., et al. 2018. Life cycle environmental impact of onshore and offshore wind farms in Texas. Sustainability 10 (6): 2022.

50. Tazi, N., Kim, J., Bouzidi, Y., et al. 2019. Waste and material flow analysis in the end-of-life wind energy system. Resources, Conservation and Recycling 145: 199-207.

51. Allwood, J. 2016. A bright future for UK steel: A strategy for innovation and leadership through up-cycling and integration [online]. Cambridge: University of Cambridge. Available from: https://www.cam.ac.uk/system/files/a_bright_future_for_uk_steel 2.pdf [Accessed 18 November 2018].

52. Sustainable Businesses. 2018. About Metal Recycling: An Introduction to Scrap Metal Recycling. Available from: https://www. thebalancesmb.com/about-metal-recycling-2877921 [Accessed 18 November 2018].

53. ASM Metal Recycling. 2017. Metal Recycling Guide. Available from: https://www.asm-recycling.co.uk/blog/metal-recyclingguide/ [Accessed 18 November 2018].
54. Danish Wind Industry Association. 2003. Offshore Foundations: Monopile. Available from: https://xn--drmstrre-64ad.dk/wp-conte nt/wind/miller/windpower\%20web/en/tour/rd/monopile.htm [Accessed 18 November 2018].

55. RSK. 2012. Rampion Offshore Wind Farm: ES Section 5 - EIA Process Appendix 5.1 [online]. Report number: 6.3.5i. Helsby. Available from: https://infrastructure.planninginspectorate.gov. uk/wp-content/ipc/uploads/projects/EN010032/EN010032-00145 2-6.3.5i\%20EIA\%20Process\%20Appendix\%205.1.pdf [Accessed 18 November 2018].

56. Renewable Energy Focus. 2017. Industry Perspective Preview: What to do with "Spent" Wind Turbine Blades? Available from: https://www.renewableenergyfocus.com/view/46397/industryperspective-preview-what-to-do-with-spent-wind-turbine-blade s/ [Accessed 18 November 2018].

57. Job, S., Leeke, G., Mativenga, P. T., et al. 2016. Composites recycling: Where are we now? [online]. Retrieved from https://compo sitesuk.co.uk/system/files/documents/Recycling\%20Report\%20 2016.pdf [Accessed 16 February 2018].

58. University of Strathclyde. 2014. Recycled Glass Fibre for Costeffective Composites. Available from: https://www.strath.ac.uk/ rkes/fly/recycledglassfibreforcost-effectivecomposites/ [Accessed 18 November 2018].

59. Copper Development Association. 2018. Europe's Demand for Copper is Increasingly Met by Recycling. Available from: https ://copperalliance.org.uk/benefits-copper/recycling/ [Accessed 18 November 2018].

60. Falconer, I. 2009. Metals Required for the UK's Low Carbon Energy System: The case of copper usage in wind farms. Dissertation. MSc, University of Exeter: Exeter, England, UK.

61. Alfed. 2012. UK Aluminium Industry Fact Sheet 5: Aluminium Recycling [online]. London: Aluminium Federation. Available from: www.alfed.org.uk/files/Factsheets/5-aluminium-recycling. pdf [Accessed 18 November 2018].

62. Environmental Technology. 2018. How Many Times Can Plastic Be Recycled? Available from: https://www.envirotech-online.com/ news/environmental-laboratory/7/breaking-news/how-many-times -can-plastic-be-recycled/46064 [Accessed 18 November 2018].

63. The ImpEE Project. 2005. Recycling of Plastics. Available from: https://www-g.eng.cam.ac.uk/impee/topics/RecyclePlastics/files/ Recycling\%20Plastic\%20v3\%20PDF.pdf [Accessed 18 November 2018].

64. Francis, R. 2016. Recycling of Polymers: Methods, Characterisation and Applications; John Wiley \& Sons: Hoboken, New Jersey, USA.

65. Power Magazine. 2016. Wind Turbine Repowering is on the Horizon. Available from: https://www.powermag.com/wind-turbinerepowering-horizon/?pagenum $=1$ [Accessed 18 November 2018].

66. North American Windpower. 2017. Renew. Reuse. Repower. January. 13 (12): 1-34.

67. Wind Power Monthly. 2018. Three Steps to Turbine Repowering. Available from: https://www.windpowermonthly.com/artic le/1456033/three-steps-turbine-repowering [Accessed 18 November 2018].

68. Walton, S. and Parker, D. 2008. The Potential for Remanufacturing of Wind Turbines. Centre for Remanufacturing and Reuse, Aylesbury, Buckinghamshire, England, UK

69. Bank, L. C., Arias, F. R., Yazdanbakhsh, A., et al. 2018. Concepts for Reusing Composite Materials from Decommissioned Wind Turbine Blades in Affordable Housing. Recycling [online]. 3 (1). [Accessed 18 November 2018].

70. Wind Europe. 2017. Discussion Paper on managing composite blade waste [online]. Windeurope. Available from: https://winde urope.org/wp-content/uploads/files/policy/topics/sustainabi lity/Discussion-paper-on-blade-waste-treatment-20170418.pdf [Accessed 18 November 2018]. 
71. Beauson, J., and Brøndsted, P. 2016. Wind Turbine Blades: An End of Life Perspective. In: Ostachowicz, W., McGugan, M. and SchröderHinrichs, J. U. (2016) MARE-WINT: New Materials and Reliability in Offshore Wind Turbine Technology. Cham: Springer, pp. 421-432.

72. Fiberline. 2010. Breakthrough: Recycling of Fibreglass is now a Reality. Available from: https://fiberline.com/news/miljoe/breakthroughrecycling-fibreglass-now-reality [Accessed 18 November 2018].

73. Halliwell, S. 2006. End of Life Options for Composite Waste End of Life Options for Composite Waste Recycle, Reuse or Dispose? National Composites Network Best Practice Guide [online]. National Composites Network. Available from: https:// doi.org/10.1021/ja0395846 [Accessed 18 November 2018].

74. De Matos, R.M.M.P. 2016. Steel Towers for Wind Turbines. Thesis. PhD. University of Coimbra, Portugal.
75. Neocomp. 2018. Our Services. Retrieved from https://www.neoco $\mathrm{mp} . \mathrm{eu} / \mathrm{de} /$ Leistungen [Accessed 18 November 2018].

76. Vox. 2017. These huge new wind turbines are a marvel. They're also the future. [online]. New York City: Vox. Retrieved from https://www.vox.com/energy-and-environment/2018/3/8/17084 158/wind-turbine-power-energy-blades [Accessed 16 September 2018].

77. Cemfree. 2018. Zero-cement Concrete that can Save up to $88 \%$ in Embodied $\mathrm{CO}_{2}$ Compared to a Conventional Mix. Retrieved from https://dbgholdings.com/cemfree/ [Accessed 18 November 2018].

Publisher's Note Springer Nature remains neutral with regard to jurisdictional claims in published maps and institutional affiliations. 